
C., Aura Tortosa, J. E. y Villaverde Bonilla, V. (2022). Abric de la Ratlla del Bubo (Crevillent, Alicante). Resultados de las campañas de 1986-1991. Nuevos datos sobre su secuencia paleolítica. Lucentum, XLI,, 9-33. https://doi.org/10.14198/LVCENTVM.20759

\title{
Abric de la Ratlla del Bubo (Crevillent, Alicante). Resultados de las campañas de 1986-1991. Nuevos datos sobre su secuencia paleolítica
}

\author{
Abric de la Ratlla del Bubo (Crevillent, Alicante). Results of the 1986-1991 \\ campaigns. New data on its palaeolithic sequence
}

\begin{abstract}
Álvaro Martínez-Alfaro, alvaro.martinez-alfaro@uv.es, https://orcid.org/0000-0003-1160-7126, Universitat de València, España Ernestina Badal García, ernestina.badal@uv.es, https://orcid.org/0000-0002-8296-1870, Universitat de València, España Aleix Eixea Vilanova, Alejo.Eixea@uv.es, https://orcid.org/0000-0002-6228-4294. Universitat de València, España Carmen María Martínez-Varea, Carmen.M.Martinez@uv.es, https://orcid.org/0000-0003-0680-2605, Universitat de València, España, Institut des Sciences de l'Évolution - ISEM (UMR 5554), Université Montpellier, Francia

Cristina Real Margalef, Cristina.Real@uv.es, https://orcid.org/0000-0002-5667-1474, Universitat de València, España

J. Emili Aura Tortosa, J.Emili.Aura@uv.es, https://orcid.org/0000-0003-1074-4495, Universitat de València, España Valentín Villaverde Bonilla, Valentin.villaverde@uv.es, https://orcid.org/0000-0002-2876-0306, Universitat de València, España
\end{abstract}

\section{Resumen}

El Abric de la Ratlla del Bubo (Crevillent, Alicante) es uno de los yacimientos clave para el conocimiento del Paleolítico superior en el área central del Mediterráneo ibérico, especialmente en lo que a sus fases iniciales se refiere. El yacimiento ha sido objeto de varias intervenciones arqueológicas, tanto clandestinas como científicas. Sin embargo, hasta este trabajo, la información disponible era parcial y, en muchos casos, remitía a materiales sin referencia estratigráfica. En este estudio se exponen los resultados del análisis del material lítico, del registro vegetal y de la fauna recuperada en las campañas de 1986 a 1991. Además, se presenta una amplia serie de dataciones radiocarbónicas por AMS. A partir de toda esta información, ha sido posible establecer la secuencia de ocupación de los cuatro niveles a techo de la estratigrafía del abrigo excavados durante las campañas a estudio. Los tres niveles inferiores documentados, a partir de la tecno-tipología lítica y la cronología, han podido ser definidos y relacionados con el tecnocomplejo Gravetiense. El nivel superior carece de datación ${ }^{14} \mathrm{C}$ y ha presentado mayor dificultad de adscripción; las características del material lítico nos llevan a relacionarlo con ocupaciones del Solútreo-gravetiense. Por otro lado, una parte fundamental del trabajo son los resultados del análisis de los restos arqueobotánicos y faunísticos que son coherentes con la propuesta secuencial y permiten comprender de forma precisa la ocupación humana de la zona, además de la utilización de los recursos durante el Gravetiense y el Solútreogravetiense. Uno de los resultados de mayor relevancia del trabajo es que la secuencia de ocupación planteada modifica la adscripción preliminar realizada a principios de los años noventa del siglo XX. El estudio permitirá mejorar la información

\begin{abstract}
The rock shelter of Ratlla del Bubo (Crevillent, Alicante) is one of the key sites for the knowledge of the Upper Palaeolithic in the central Iberian Mediterranean basin, especially regarding its initial phases. Several archaeological fieldworks has been carried out in the site, both clandestine and scientific. However, before this paper, the information available was partial and, in many cases, referred to remains without stratigraphic reference. This study presents the results of the analysis of the lithic, archaeobotanical and faunal material recovered during the 1986-1991 campaigns. In addition, we present an extensive series of AMS radiocarbon dates. On the basis of all this information, it has been possible to establish the occupational sequence of the four levels on the top of the rock shelter stratigraphy excavated during the studied campaings. The three lower levels documented, based on the lithic techno-typology and chronology, have been defined and related to the Gravettian technocomplex. The upper-level lacks ${ }^{14} \mathrm{C}$ dating and it has been more difficult to assign; the characteristics of the lithic material lead us to link it to Solútreo-Gravettian occupations. On the other hand, a fundamental part of the paper are the results of the analysis of the archaeobotanical and faunal materials, which are coherent with the proposed sequence and allow a precise understanding of the human occupation of the area, as well as the use of resources during the Gravettian and Solútreo-Gravettian periods. One of the most relevant results of the study is that the proposed occupation sequence modifies the preliminary ascription made at the beginning of the 1990s. The study will improve the information currently available for the Early Upper Palaeolithic in the Iberian Mediterranean basin and, especially, in its central area.
\end{abstract}

Financiación:Este trabajo se ha realizado en el marco de los proyectos de investigación HAR2017-85153-P del Ministerio de Ciencia e Innovación y PROMETEO2017/060 de la Generalitat Valenciana. 
disponible hasta ahora para el Paleolítico superior inicial en la fachada mediterránea ibérica y, especialmente, en su área central.

Palabras clave. Abric Ratlla del Bubo; Paleolítico superior; Gravetiense; Solútreo-gravetiense; fachada mediterránea ibérica.
Key words. Abric Ratlla del Bubo; Upper Palaeolithic; Gravettian, Solutreo-gravettian; Iberian Mediterranean basin.

\section{INTRODUCCIÓN}

El Abric de la Ratlla del Bubo (Crevillent, Alicante) constituye un enclave de alto interés para el conocimiento del hábitat en el Paleolítico superior de la región central mediterránea ibérica, debido a su situación geográfica, al sur del País Valenciano y muy cerca de la parte septentrional de Murcia. Hasta la realización de este trabajo la secuencia del yacimiento carecía de una precisa documentación crono-estratigráfica, paleoambiental y de sus ocupaciones humanas.

El objetivo de este trabajo es dar a conocer de manera íntegra los resultados del estudio tecno-tipológico del material lítico, del registro vegetal (materiales antracológicos y carpológicos) y el análisis de la fauna recuperada. Además, se presenta un importante lote de nuevas dataciones que resultan esenciales para la evaluación de la secuencia. Todos estos materiales corresponden a las campañas realizadas entre 1986 y 1991. Finalmente, se realiza una revisión de la secuencia de ocupación en base a los resultados de la industria lítica y su relación con la nueva serie de dataciones por radiocarbono.

A la luz de los resultados obtenidos, este trabajo pone en valor una de las secuencias más relevantes con niveles del Paleolítico superior inicial en la región central del Mediterráneo ibérico. Todo ello, en un contexto en el que en los últimos años se ha llevado a cabo un avance destacable en el conocimiento de las primeras sociedades de humanos modernos que poblaron esta zona peninsular, a saber: la incorporación de nuevas secuencias como los niveles basales de la Cova de les Cendres (Teulada, Alicante) (Villaverde et al., 2019) o las de los abrigos de La Boja y Finca de doña Martina (Mula, Murcia) (Zilhão et al., 2017), la revisión y nuevas intervenciones en la Cova de les Malladetes (Barx, Valencia) (Villaverde et al., 2021) o las revisiones a nivel secuencial para el Auriñaciense (Martínez-Alfaro, Bel y Villaverde, 2021) y Gravetiense (Villaverde, Martínez-Alfaro y Bel, 2021), entre otros. En un ámbito más inmediato, los datos ofrecidos por la secuencia de la Ratlla del Bubo permiten valorar con una nueva perspectiva los hallazgos realizados en el cercano yacimiento del Corral de les Paleres (Molina et al., 2020).

\section{EL ABRIC DE LA RATLLA DEL BUBO Y SU INVESTIGACIÓN}

El Abric de la Ratlla del Bubo, también conocido en la bibliografía como Ratlla del Mussol, (UTM Huso:
30 X689242 Y4238869 Z390m) se localiza en el término municipal de Crevillent (Alicante), en la vertiente sudeste de la Serra de Crevillent, muy próximo a la cabecera del Barranc de la Rambla a unos 400 m s.n.m. (Fig. 1: a y b). Esta sierra es una estructura anticlinal que en su flanco sur presenta calizas margosas en contacto mecánico con el Triásico y Prebético. Geológicamente es una cavidad kárstica de una superficie de $127 \mathrm{~m}^{2}$, que se emplaza en un amplio afloramiento de calizas jurásicas, marinas, fosilíferas y estructuralmente rejugadas por los empujes tectónicos y halocinéticos del Triásico infrayacente. El yacimiento se encuentra en contexto bioclimático termomediterráneo superior con ombroclima semirárido, es decir, una media de precipitación anual entre los 200-350 mm. La vegetación actual forma un matorral claro con espino negro (Rhamnus lycioides), lentisco (Pistacia lentiscus), oroval (Withania frutescens), algún pino carrasco (Pinus halepensis) y un espartal de albardín (Lygeum spartum) y esparto (Stipa tenacissima) (Fig. 1: b).

En lo que respecta a los trabajos de excavación e investigación del abrigo, la primera referencia al yacimiento se incluyó en un trabajo de revisión del Gravetiense valenciano realizado a comienzos de los años ochenta (Miralles, 1982). En el mismo se dio cuenta de un reducido lote de materiales que remitían a tres niveles basales, aunque desgraciadamente definidos a partir de excavaciones clandestinas poco fiables. En total, 37 piezas retocadas en las que están presentes materiales de dorso coherentes con su adscripción al Gravetiense, además de un importante lote de piezas que podrían corresponder al Auriñaciense: raspadores carenados y en hocico. Poco tiempo después, en el año 1984, se llevó a cabo una excavación de urgencia en el yacimiento, bajo la dirección de G. Iturbe y J. L. Román, y con posterioridad los trabajos de campo continuaron entre 1986 y 1991, bajo la dirección de V. Villaverde y J. E. Aura. Durante estas últimas excavaciones la reiterada acción de excavadores clandestinos alteró de manera significativa el área excavada, siendo necesarias continuas rectificaciones de los cortes estratigráficos y limpiezas del área en proceso de excavación. La pérdida sustancial de información obligó a detener el trabajo de campo.

El material recuperado en las diferentes campañas ha sido objeto solo de publicación parcial. De la campaña de 1984, se conoce la composición del material lítico que se obtuvo en la base de la secuencia, en una zona de $3 \mathrm{~m}^{2}$ de superficie que no había sido afectada por la actividad de los excavadores clandestinos, y consiste en una aproximación al registro lítico y la identificación de una estructura de combustión parcialmente afectada. 

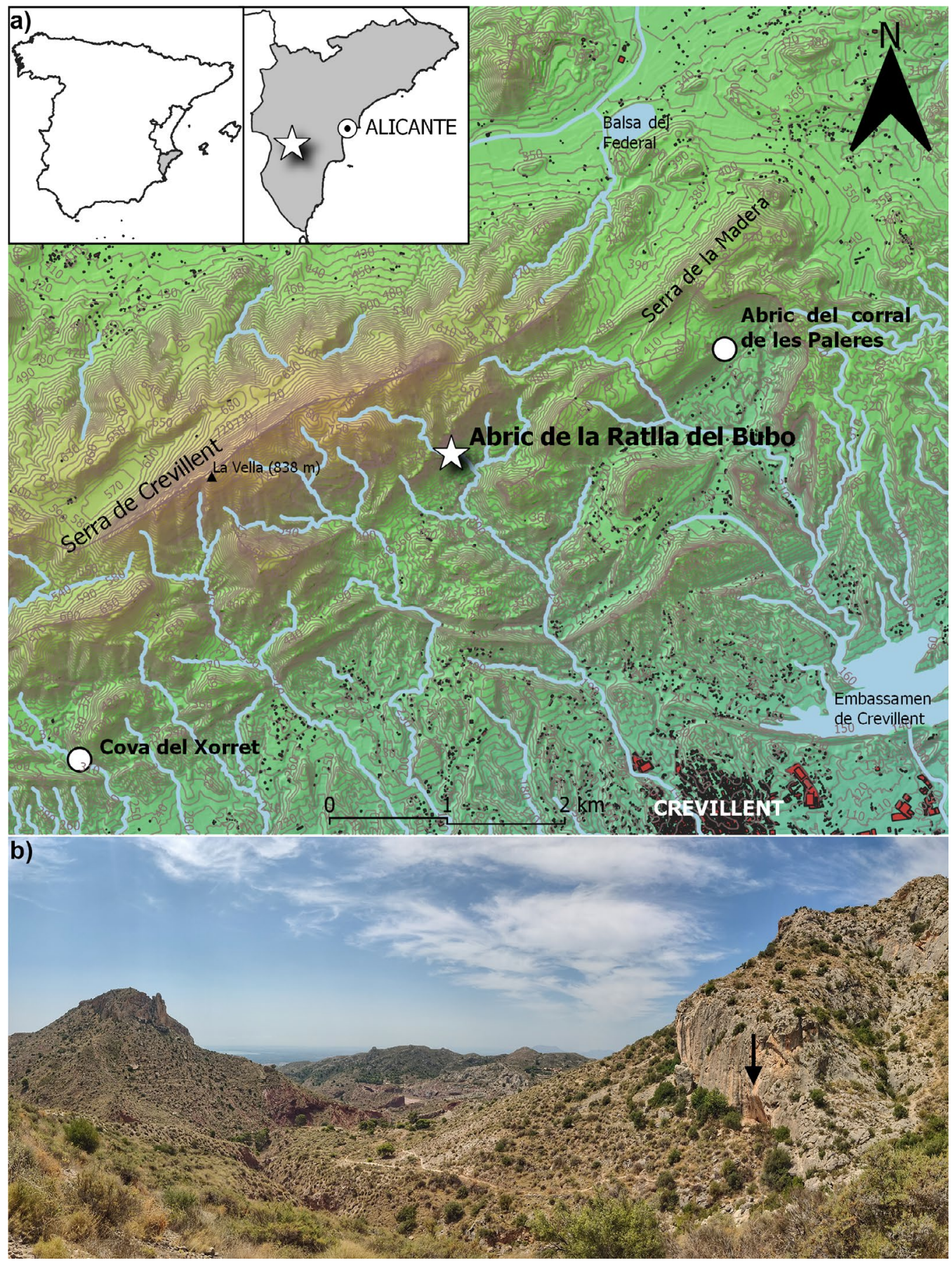

Figura 1: a) Localización del Abric de la Ratlla del Bubo y otros yacimientos mencionados en el texto ubicados en la Serra de Crevillent (realización propia a partir de Bases Cartográficas y Topográficas del IGN); b) Vista del yacimiento desde la cabecera del Barranc de la Rambla (fotografía: V. Martínez-Rubio)

En total, se documentaron 81 piezas retocadas que, por sus características tipológicas pudieron relacionarse con el Auriñaciense evolucionado - raspadores carenados y en hocico, además de algunas laminitas de tipo Dufour-(Iturbe y Cortell, 1992). De las campañas de 1986 a 1991 el grueso de la información ha permanecido prácticamente inédito hasta este trabajo. Se publicó un hogar documentado en la parte superior del nivel II, que fue objeto de destrucción parcial por excavaciones clandestinas posteriores antes de que pudiera ser completamente excavado. Del mismo se obtuvo una datación a partir de diversos carbones, todos ellos del género Juniperus sp., que proporcionó un resultado de $17.360 \pm 180$ BP (Ly - 5219). El estudio antracológico y de la estructura de combustión (Soler et al., 1990) fue posteriormente ampliado por la publicación de algunos datos de la fauna asociada (Villaverde y Martínez-Valle, 1995) y un análisis más detallado de la estructura de combustión (Soler, 2003). Finalmente, se ha realizado también un análisis de materias primas 
silíceas correspondientes a este yacimiento, que incluye los materiales de las excavaciones y de las colecciones clandestinas (Menargues, 2000; 2005), así como del conjunto de los materiales líticos depositados en el Museu Arqueològic Municipal de Novelda (Menargues y Navarro, 2001), con un total de 1003 restos de los que 100 se clasifican por la lista-tipo del material retocado.

\section{MATERIALES Y MÉTODOS}

Se analiza la cronología, los restos vegetales, de fauna y de industria lítica recuperados durante las campañas de excavación desarrolladas entre 1986 y 1991. Los trabajos de excavación se realizaron sobre un área inicial de aproximadamente $16 \mathrm{~m}^{2}$, que fue reduciéndose progresivamente hasta los $12 \mathrm{~m}^{2}$ (Fig. 2: a). Como resultado de estas excavaciones se identificaron cuatro niveles arqueológicos (I al IV), caracterizados por una estructura sedimentaria compleja, con variaciones laterales en determinados momentos, y la presencia de bloques desprendidos de la visera. Los contactos del nivel III son difusos tanto en su inicio como en su fin, motivo por el que el nivel III fue considerado durante su excavación como un nivel de transición ante la imposibilidad de aislarlo con seguridad. En esta excavación no se llegó a la base de la secuencia, y ni siquiera se alcanzaron los niveles adscritos al Auriñaciense en la campaña de 1984. La secuencia estratigráfica fue descrita in situ por la Dra. María Pilar Fumanal en los siguientes términos (Fig. 2: b):

- Nivel I. Sedimento limoso de color amarillo rojizo en el que se intercalan zonas de cenizas. Presencia de fracción gruesa muy angulosa y con poca alteración, alternada con momentos de menor intensidad de fracción en la que aparecen numerosos carbonatos.

- Nivel II. Se inicia con un cambio sedimentario que viene dado por la aparición de un paquete de estructura laminada, líneas de cenizas. La textura es limosa amarillenta con una fracción con proporción equilibrada entre gruesos y finos, que adquiere una disposición predominantemente horizontal, y dependiendo del área, una disposición heterogénea, con presencia en determinadas zonas de bloques. Conforme avanza en profundidad la secuencia, en algunas áreas aparecen manchones grises caracterizados por la riqueza lítica y de carbones.

- Nivel III. Su inicio viene marcado por una línea bastante continua de bloques y notables cambios de color y textura. Línea de potencia variable con bloques y fracción media que adquiere mayor potencia hacia la pared del abrigo. La coloración y textura general del estrato no es fácilmente diferenciable, quizá algo más suelta que el estrato II. La fracción ofrece un resultado de cantos gruesos, angulosos, subhorizontales a la base, y fracción media y pequeña. La base del nivel coincide con una especie de lecho de bloques desprendidos de la visera. Es el nivel que más dificultades presentó a la hora de su levantamiento por el contacto entre los estratos II y IV. El material aparece algo patinado lo que hace pensar en una lenta sedimentación.

- Nivel IV. Presenta una complejidad interna, grosso modo de coloración marrón a grisácea y con fracción. Se caracteriza una fase central compuesta por bloques horizontales angulosos y desprendidos de la visera, junto a algo de fracción pequeña de aristas vivas, y un depósito delgado en contacto con el nivel III, formado por cantos angulosos, a veces, en forma de plaquetas, englobados en la matriz arenolimosa. Su base se corresponde con una fracción fina, aunque aparecen pequeños cantos muy angulosos con una disposición horizontal y poco definida junto a un cierto cambio de tonalidad. Destaca la abundancia de materiales arqueológicos.

En el estudio del material lítico se han analizado todos los restos recuperados en los niveles IV al I. Los problemas sedimentarios relacionados con el nivel III, los resultados de las dataciones radiocarbónicas y la baja densidad de material desaconsejan un análisis diacrónico de la secuencia industrial. Por ello, los resultados se exponen agrupados en dos bloques: niveles IV al II y nivel I. El estudio se ha realizado a partir de una aproximación tecnológica (Inizan et al., 1995; Pelegrin, 1995, 2000; Tixier et al., 1980) y tipológica (SonnevilleBordes y Perrot, 1954; 1955; 1956a; 1956b). A su vez, se ha hecho una caracterización preliminar de las materias primas silíceas, que consiste en un análisis macroscópico (Masson, 1979) mediante el empleo de una lupa binocular con un aumento de 20x o 40x, y la utilización de una tabla de color Munsell. Se ha registrado el color, textura, impurezas y características del córtex creando agrupaciones de materia o tipos en base a sus características petrográficas.

En lo que concierne al registro vegetal, se recuperaron los restos durante las excavaciones de 1987, 1990 y 1991. 1132 fragmentos de carbón fueron identificados y publicados (Badal, 1991; 1995; Badal y Carrión, 2001), pero las muestras de las campañas de 1990 y 1991 quedaron pendientes de análisis. El método de recogida fue mediante tamizado en seco de los sedimentos procedentes de $16 \mathrm{~m}^{2}$. Del hogar situado en el nivel II, se recuperaron 55 fragmentos de carbón y se guardó una muestra de \pm 3 litros de sedimento que ha sido analizada en 2020 y donde se han identificado 64 carbones. Se ha completado el análisis de los carbones con la identificación total de 1907 fragmentos, bajo un microscopio metalográfico Leica DM6000M. De ese conjunto, al menos 84 son históricos y responden a alteraciones tafonómicas que luego analizaremos. Además, con el objetivo de localizar restos carpológicos $\mathrm{u}$ otros elementos vegetales no leñosos se han triado 69 muestras de los niveles II, III y IV bajo lupa binocular Leica M165C.

La identificación taxonómica de los restos arqueobotánicos se ha realizado con referencia a la 
a)

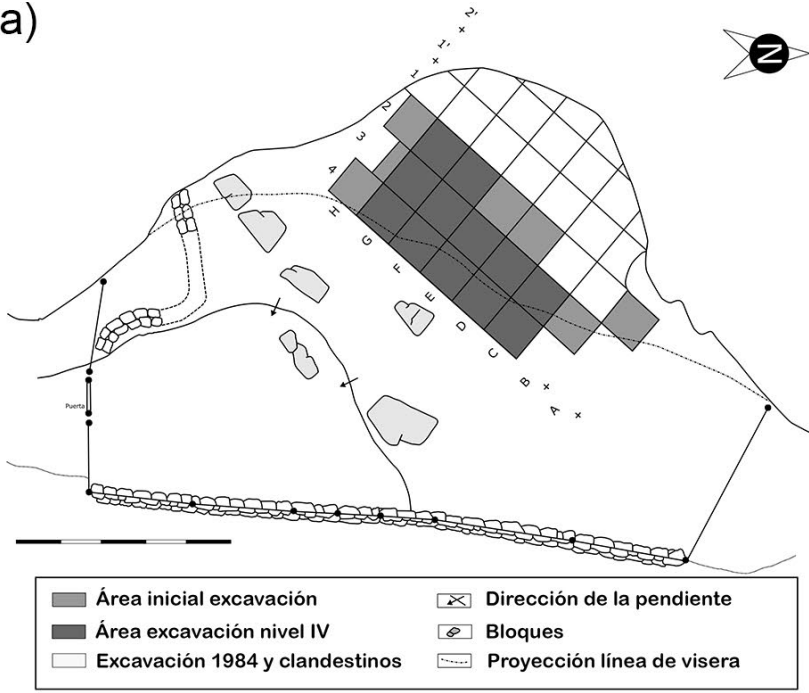

b)

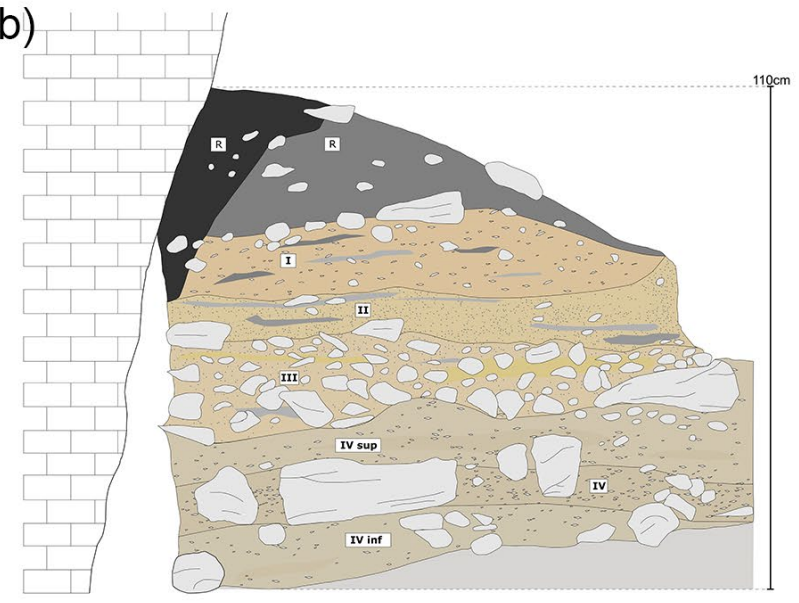

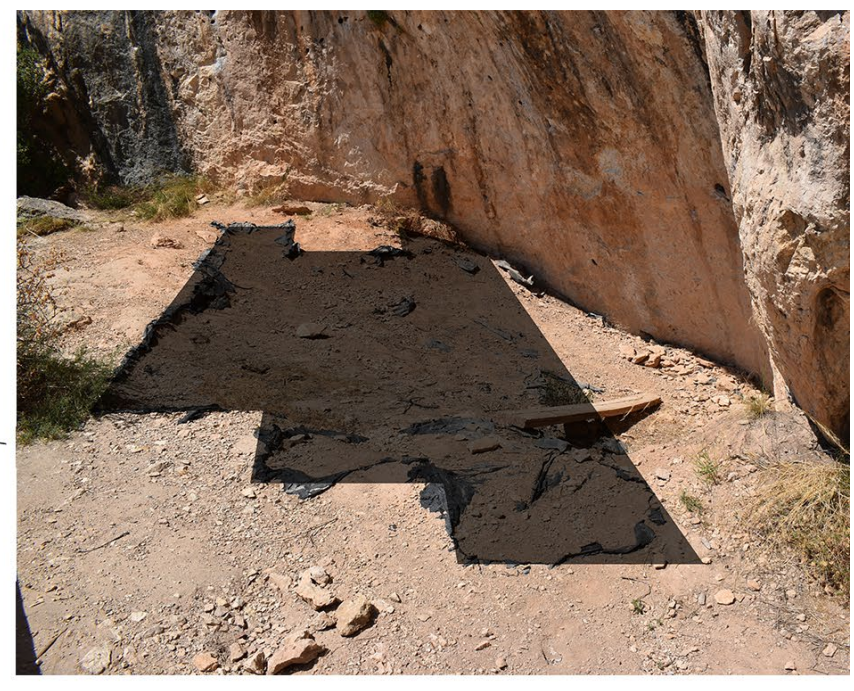

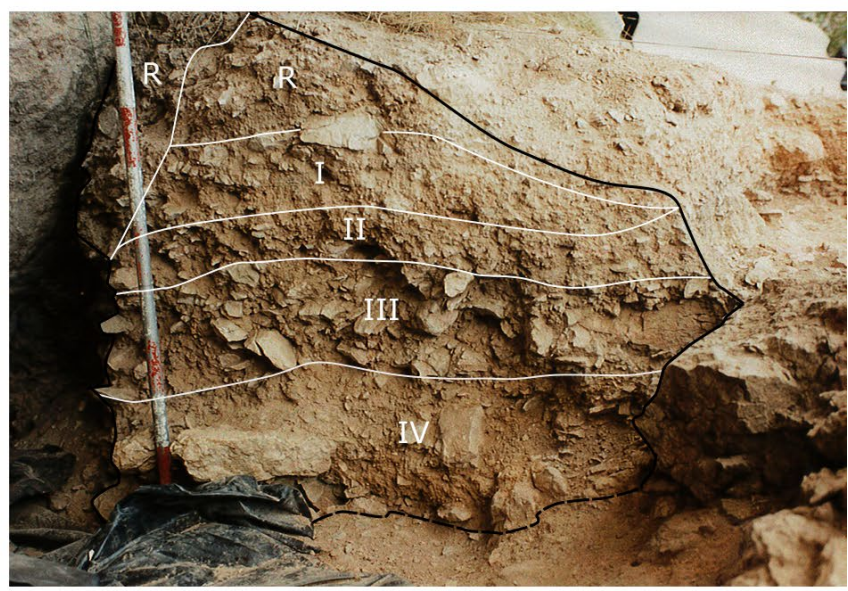

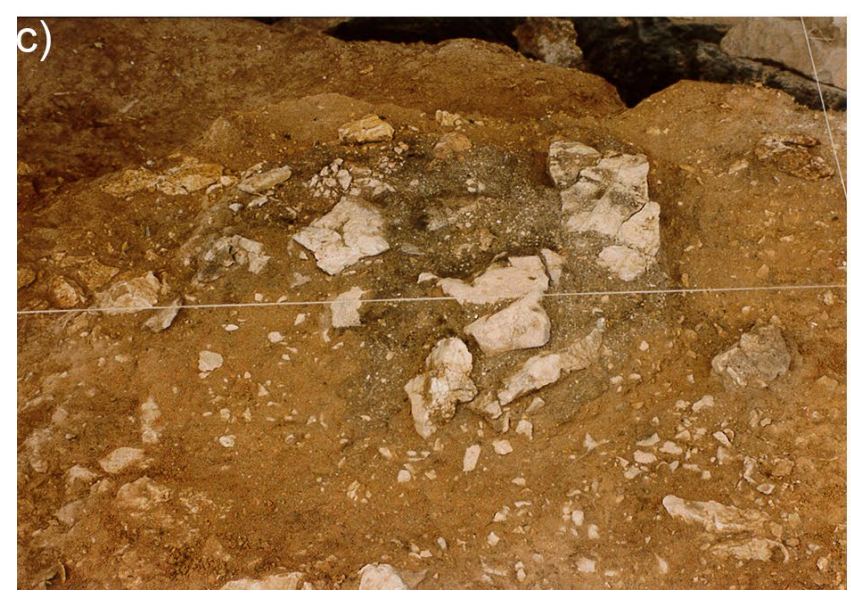

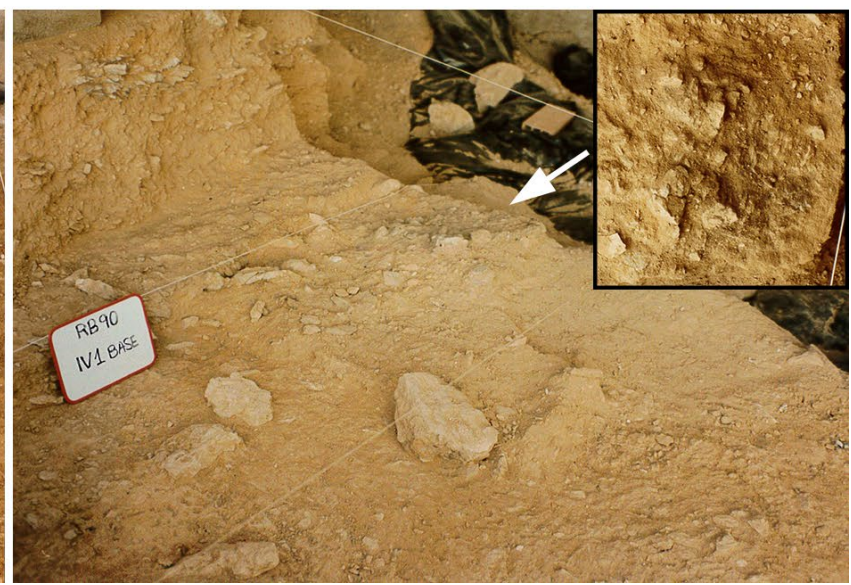

Figura 2: a) Planta del yacimiento y área de excavación (redibujado a partir de Soler, 2003); b) Corte estratigráfico del sagital izquierdo en cuadro A-1; c) Hogares en proceso de excavación: izquierda nivel III-IV y derecha nivel IV-1 base

colección de maderas, carbones y semillas del Laboratori d'Arqueologia Milagro Gil-Mascarell de la Universitat de València. Para la obtención de fotografías de los restos antracológicos se ha empleado un microscopio electrónico de barrido Hitachi S-4800 en el Servicio Central de Soporte a la Investigación Experimental de la Universitat de València. La identificación botánica y el recuento de los taxones ha seguido los métodos habituales (Badal, 1992; Chabal, 1988).

La revisión de la secuencia arqueológica requería una serie de dataciones radiocarbónicas, con el método AMS, ya que la única fecha disponible fue obtenida en los años 80 con el método convencional de un agregado de 10 gr de carbón de Juniperus sp. Para la nueva serie 
de dataciones, la selección de carbones persiguió los siguientes objetivos:

A. Obtener la secuencia crono-estratigráfica mediante la selección de una serie de 10 carbones del taxón dominante en todos los niveles arqueológicos, es decir, de Juniperus sp. Los carbones proceden de distintas profundidades de base a techo y corresponden a los niveles IV al II.

B. Resolver si las plantas cálidas identificadas eran paleolíticas o modernas. Tal y como argumentamos en publicaciones anteriores, la presencia de taxones termófilos en la secuencia paleolítica del yacimiento nos suscitaba dudas (Badal, 2012). Así planteamos dos hipótesis alternativas: 1) en caso de resultar paleolíticas, estas dataciones respaldarían las hipótesis de los refugios en Iberia durante el último glacial; 2) si eran holocenas se demostraba que eran intrusiones modernas del nivel superficial que no presentaba interés arqueológico. Con este planteamiento se envió a datar: dos carbones de Ephedra sp. (belcho), dos de Pistacia sp. (lentisco - cornicabra) y uno de Ficus carica (higuera). Teníamos constancia de que un carbón de Olea europea procedente del yacimiento fue datado en Francia, arrojando una fecha moderna que nunca se publicó (J.-F. Terral comunicación oral). Además, siempre que esta especie ha sido datada en la península ibérica, ha reportado fechas del Holoceno (Carrión, Ntinou y Badal, 2010). Por ello, no hemos enviado a datar ninguna muestra de Olea europea.

Desde un punto de vista cronoestratigráfico, cada una de las fechas obtenidas ha sido calibrada mediante el software OxCal v4.4.2. (C) Bronk Ramsey 2020, tomando de referencia la curva de calibración atmosférica r:5 IntCal13 (Reimer et al., 2013). La cronología obtenida se ha analizado de forma crítica y se ha planteado un modelo estadístico bayesiano que consta de una única fase «Gravetiense». El modelo se ha procesado con el software OxCal v4.4.2. y ha seguido la metodología específica para este tipo de modelos (Bronk Ramsey, 2009a; 2009b; 2017).

En lo que atañe a la fauna, se han analizado todos los restos óseos procedentes de los niveles IV a II. La identificación taxonómica y anatómica de los huesos se ha realizado gracias a la colección de referencia del Laboratori d'Arqueologia Milagro Gil-Mascarell de la Universitat de València. Para la cuantificación se ha utilizado: el Número de Restos (NR), el Número de Restos Identificados (NISP) y el Número Mínimo de Individuos (NMI) (Lyman, 1994; 2008). Los restos indeterminados han sido clasificados por tallas: muy pequeña, pequeña, media y grande; y tipo de hueso: largo, esponjoso, plano y dental. Asimismo, se ha analizado su superficie en busca de modificaciones. Los restos menores de $2 \mathrm{~cm}$ se han registrado como esquirlas. Finalmente, la clasificación de las fracturas se basa en Villa y Mahieu (1991) y de los morfotipos de fractura en Real (2017). Las marcas de corte, termoalteraciones y alteraciones postdeposicionales se han clasificado según la bibliografía existente (Binford, 1981; Bromage y Boyde, 1984; Lyman, 1994; Pérez-Ripoll, 1992; Potts y Shipman, 1981; Shipman y Rose, 1983; Soulier y Morin, 2016; Stiner et al., 1995; Théry-Parisot et al., 2004; Vettese et al., 2020).

\section{INDUSTRIA LÍTICA}

El conjunto lítico recuperado asciende a 4565 restos y ha sido la base fundamental para la adscripción de los niveles a los tecnocomplejos Gravetiense y Solútreo-gravetiense.

\subsection{MATERIAS PRIMAS}

La materia prima dominante en todos los niveles analizados es el sílex con unos valores que superan el $98 \%$ en todos los casos sin apenas variación diacrónica. Otras litologías como la caliza, cuarcita, jaspe y arenisca son esporádicas. Esta composición resulta lógica, teniendo en cuenta la ubicación del yacimiento en la Serra de Crevillent y su entorno, en el que existen numerosos afloramientos de sílex (Menargues, 2000; 2005; Molina, 2016; Molina et al., 2020). A pesar de que la caracterización de los tipos de sílex es aún preliminar y está en proceso la realización de distintos análisis arqueométricos - Fluorescencia de Rayos X (XRF), Difracción de Rayos X (XRD) y Análisis por Activación Neutrónica (NAA)-, se han podido diferenciar los siguientes a lo largo de la secuencia (Fig. 3):

- Tipo 1. De coloraciones anaranjadas y marrones con presencia interna de moteados blanquecinos. De textura opaca que en algunos casos es algo más translúcida, presenta un grano fino con baja presencia de inclusiones, lo que le proporciona muy buena calidad de fractura para la talla. Las zonas corticales tienen una tonalidad marrón y aparecen de forma semi-rodada. Estas características nos indican una similitud con el tipo Serreta (Molina, 2016).

- Tipo 2. Color marrón y en algunos casos con unas tonalidades más grisáceas. Además, en determinados casos presenta algunas bandas de color blanco. La textura del grano es fina, opaca y con baja presencia de inclusiones. La calidad para la talla es buena. Las superficies corticales son de coloración marrón clara y/o blanquecina y de carácter rodado.

- Tipo 3. Coloración homogénea gris oscura. Presenta un grano grueso de aspecto cuarcítico y opaco. No se aprecian inclusiones a nivel interno. La calidad para la talla es media.

- Tipo 4. Color gris translúcido de grano fino. A nivel interno presenta multitud de inclusiones (óxidos de hierro, elementos de origen biogénico, etc.) y moteados blancos. Ofrece una buena calidad para la talla. El córtex es de tonalidad blanquecina, aparece 


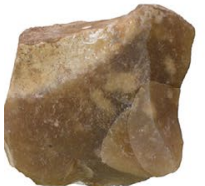

Tipo 1

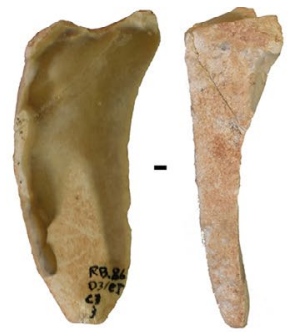

Tipo 2

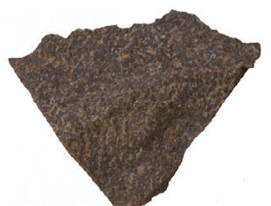

Tipo 3

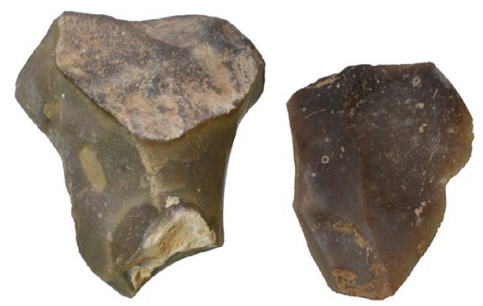

Tipo 4

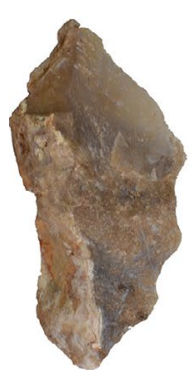

Tipo 5

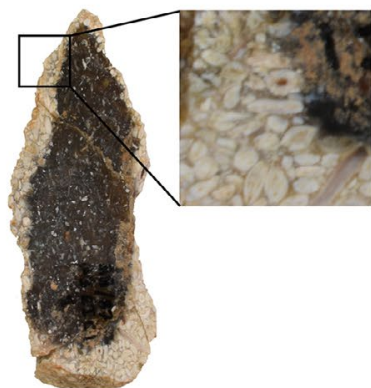

Tipo 6

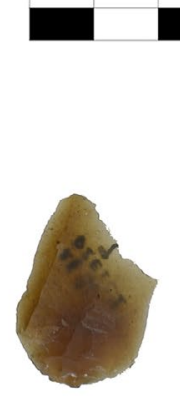

Tipo 7

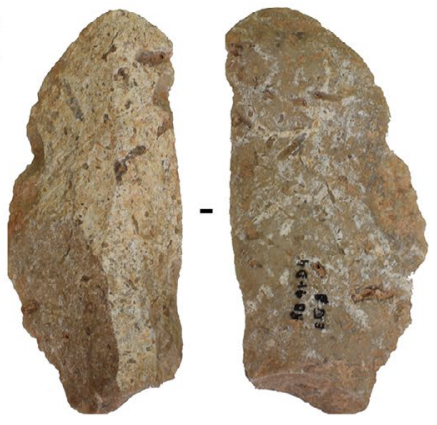

Tipo 8

Figura 3: Tipos de sílex identificados en la industria lítica de la Ratlla del Bubo

muy rodado y en algunos casos completamente pulido, probablemente de carácter marino.

- Tipo 5. Tiene una variación cromática que va del marrón y al gris claro. La textura es translúcida y presenta multitud de elementos internos, además de pequeñas oquedades fruto del mismo proceso de silicificación. A pesar de poseer una fractura de tipo concoide, la calidad para la talla es de tipo medio. Y, además, en algunos casos dichas inclusiones provocan la fractura de la pieza.

- Tipo 6. Coloraciones en tonos grises, desde una gama blanquecina pasando por una gris común hasta un grisáceo de tendencia a negro. La textura del grano es variable, desde finos hasta granos de tipo medio. La estructura es opaca y tiene una elevada proporción de inclusiones (óxidos de hierro, elementos biogénicos, microfósiles, etc.). La calidad para la talla es media-buena porque en una proporción de restos se aprecian accidentes de talla (reflejados, accidente Siret, etc.). La estructura cortical adquiere coloraciones amarronadas, posiblemente fruto de su formación en roca caja calcárea, y una morfología semi-rodada y en algunos casos mayor rugosidad.

- Tipo 7. De gamas marrones oscuras, con una estructura homogénea y textura translúcida. Se aprecian algunos elementos internos de origen biológico y, en algún caso estructura moteada. La calidad para la talla es buena, tal y como se aprecia en la fractura concoide, las ondas de los negativos y las aristas bien marcadas. El córtex es de color blanco y formato semi-rodado.

- Tipo 8. Coloración gris oscura con una textura opaca y un grano de tamaño medio-grueso de aspecto calizo. Elevada representación de elementos internos. La calidad para la talla es media y recuerda a un tipo de sílex neógeno documentado en la zona (Molina et al., 2020).

Quedan fuera del análisis aquellos elementos en los que no se ha podido determinar con precisión las características macroscópicas de la pieza. Aparte de algunos elementos que presentan algún tipo de afección postdeposicional (pátinas, concreciones, etc.), la mayor parte de los indeterminados se deben a procesos de alteración térmica vinculada con el fuego.

Los tipos de sílex identificados presentan unas cualidades para la talla buenas o medias y, exceptuando el sílex tipo 3, en todos se documenta la gestión laminar. No obstante, en los tipos con mayores intrusiones y/o grano más grueso la calidad de la fractura concoide es menor y, en los soportes y núcleos, se detectan accidentes de talla como reflejados o embotados. Por otra parte, nos parece aventurado en un estudio preliminar, abordar en profundidad las áreas de captación a las que accedieron los grupos humanos que habitaron el abrigo durante el Gravetiense y el Solútreo-gravetiense.

Como se ha indicado, la Ratlla del Bubo se enclava en un ámbito geológico rico en afloramientos de sílex, recientes estudios han contabilizado 19 de ellos, tanto en posición primaria como secundaria, en depósitos que comprenden desde Triásico (Carniense) hasta el Plioceno (Mesiniense) (Menargues, 2005; Molina et al., 2020: 18-19). Atendiendo a las superficies corticales, podemos plantear una primera propuesta de las fuentes de aprovisionamiento de los sílex, ya que el córtex aporta información útil del posible transporte que 
hayan sufrido los nódulos (Mangado, 2005). Los tipos 1,2 y 4, córtex rodado, sugieren un mayor transporte desde su afloramiento primario, su área de captación se localizaría en medios fluviales o marinos. El resto de tipos en los que ha podido ser descrito el córtex presentan un rodamiento menor, indicio de que su área de aprovisionamiento sería el afloramiento primario o su zona de desmantelamiento más inmediata. El sílex tipo 1, posiblemente tipo Serreta, es el único del que podría afirmarse su aportación exógena, localizando sus afloramientos a más de $50 \mathrm{~km}$ en línea recta, en la zona de Alcoi (Alicante). Esto no quiere decir que ninguno de los otros tipos pueda ser de origen exógeno, futuros estudios ayudarán en su determinación.

Finalmente, entre las litologías minoritarias destacan la caliza y la cuarcita, ambas materias primas se destinan casi exclusivamente a la talla de lascas y se documentan en las proximidades del yacimiento, en el mismo Barranc de la Rambla.

Al ser una zona rica en sílex el aprovisionamiento de tipos locales debió presentar un papel destacado, aunque no podamos definirlo con exactitud, que se vería complementado con sílex exógenos, pero también con otras materias con presencia testimonial en el conjunto, como las calizas y cuarcitas.

\subsection{Niveles IV AL II. AsPectos teCNOLÓGicos Y TI- POLÓGICOS}

Se han documentado un total de 2154 elementos, el número de restos del nivel II (1267) es considerablemente superior al de los niveles III (378) y IV (509), a pesar de que estos últimos presentan una mayor

\begin{tabular}{|c|c|c|c|c|c|}
\hline & & \multicolumn{3}{|c|}{ Gravetiense } & \multirow{2}{*}{$\begin{array}{c}\text { S-G } \\
\text { I }\end{array}$} \\
\hline & & IV & III* & II & \\
\hline \multirow{6}{*}{ Soportes } & Lasca & 145 & 65 & 273 & 450 \\
\hline & Lasca laminar & 27 & 22 & 53 & 119 \\
\hline & Lámina & 6 & 6 & 12 & 42 \\
\hline & Laminita & 54 & 38 & 107 & 214 \\
\hline & Astilla & 1 & 1 & 4 & 12 \\
\hline & Total & 233 & 132 & 449 & 837 \\
\hline \multirow{10}{*}{ Núcleos } & Prismático láminas y lascas laminares & & & 4 & 4 \\
\hline & Prismático de laminitas & 3 & 1 & 3 & 7 \\
\hline & Prismático de laminitas y lascas & & 1 & & 1 \\
\hline & De astillas & & & & 1 \\
\hline & De lascas (discoide) & & & & 4 \\
\hline & De lascas (otros) & 3 & & 5 & 6 \\
\hline & Informe/alterado & 1 & & & 1 \\
\hline & Fragmento & & & & 2 \\
\hline & Carenado & & 1 & & 1 \\
\hline & Total & 7 & 3 & 12 & 27 \\
\hline \multirow{12}{*}{ PAN } & Cresta & & & & \\
\hline & Semicresta & & 2 & 5 & 5 \\
\hline & Tableta & & & 1 & \\
\hline & Semitableta & & & & 3 \\
\hline & PPP & 13 & 8 & 28 & 46 \\
\hline & $\mathrm{PPO}$ & & 1 & 2 & 3 \\
\hline & Arista & 8 & 10 & 17 & 25 \\
\hline & Cornisa & & & & 4 \\
\hline & Total & 21 & 21 & 53 & 86 \\
\hline & Debris & 248 & 220 & 753 & 1463 \\
\hline & Canto/bloque & & 1 & & \\
\hline & TOTAL & 509 & 378 & 1267 & 2414 \\
\hline
\end{tabular}

Figura 4: Industria lítica: soportes, núcleos, productos de acondicionamiento de núcleo (PAN) y debris por nivel. Totales agrupados por categoría. (S-G: Solútreo-gravetiense, PPP: Plano de percusión principal, PPO: Plano de percusión oblicuo) * Incluye capas de transición II-III y III-IV 
potencia estratigráfica. Una parte importante de los restos corresponde al debris (50-60\%) (Fig. 4).

Como es habitual en las industrias líticas del Paleolítico superior, el objetivo principal de la talla es la producción de soportes laminares. La configuración de los núcleos laminares se lleva a cabo mediante la extracción de lascas de decalotado cuyo porcentaje varía entre el $1,1 \%$ y $1,3 \%$ de los niveles II y IV respectivamente. Los soportes de segundo orden con un alto porcentaje cortical son mayoritariamente lascas. Éstos muestran una presencia constante en los tres niveles y se vinculan también al pelado de los nódulos. Los productos parcialmente corticales van incrementando su presencia conforme disminuye la cantidad de córtex en su superficie. La presencia de córtex en los soportes laminares fundamentalmente es residual, inferior al $20 \%$. Ello debe ser relacionado más con la recuperación de zonas corticales de los núcleos, durante la fase de plena producción, que con una etapa de preparación. En términos diacrónicos, no hay cambios substanciales entre unos niveles y otros, solo mencionar que el nivel IV tiene ligeramente más proporción de elementos corticales, pero tal vez por el menor número de efectivos. Es importante señalar que la reducida extensión de la superficie excavada obliga, tanto en estos niveles como en el nivel a techo, a la prudencia en este tipo de apreciaciones; sin embargo, creemos que la cadena operativa debió desarrollarse al completo en el abrigo. El registro disponible indica que al menos una parte de los nódulos debieron ser aportados sin una pre-configuración, documentándose la talla desde sus primeros estadios.

A partir de los 21 núcleos cuya lectura tecnológica ha sido posible, se han determinado, al menos, dos tipos de gestión de la talla: producción laminar y producción de lascas. En lo que respecta al esquema de talla laminar, los núcleos de láminas son los menos habituales debido al avanzado estado de reducción de algunos de ellos y al escaso desarrollo métrico de algunos nódulos. La producción de láminas se complementa con la extracción de lascas laminares por su menor desarrollo longitudinal. Todos los núcleos laminares, excepto uno de tipo raspador-carenado, son prismáticos (Fig. 4). No se ha observado una elevada complejidad técnica en la explotación de estos núcleos, se aprovecha la morfología de los nódulos o lascas sobre los que se configuran. Por norma general, presentan una o dos caras de explotación unipolares y en menor proporción bipolares y planos secantes. El inicio de explotación se caracteriza por aprovechar los meplats laterales como guía para la primera extracción laminar, otros sistemas que necesitan mayor preparación como la configuración de crestas solo se ha documentado a partir de siete semicrestas en los niveles II (5) y III (2). Se ha recuperado un nutrido conjunto de productos de mantenimiento de los núcleos, especialmente los destinados a rectificar las superficies de lascado de los núcleos. Prácticamente no se han documentado mantenimientos de las plataformas de percusión, a excepción de una tableta en el nivel II. Son habituales las rectificaciones de las superficies de debitado para eliminar embotados y reflejados. El método más repetido es la extracción de flancos de núcleo desde el plano de percusión principal con lo que se consigue recuperar toda la superficie. Las aristas también son frecuentes para este tipo de mantenimiento, pero en este caso es una reparación parcial. Finalmente, los flancos de núcleo oblicuos o laterales son esporádicos, éstos cambian la dirección de la talla tras la rectificación; solo hay tres piezas de este tipo. En el nivel II se observa una mayor complejidad, tanto en la preparación de la talla laminar como en el mantenimiento de los núcleos.

Al tratarse de una zona rica en sílex, algunos núcleos laminares no se agotaron antes de su abandono. En otros, sin embargo, cuando la extracción de laminitas se encontraba al límite de las posibilidades se produjo un cambio en la gestión y se orientaron a la producción de lascas. Ya sea por la necesidad de obtener lascas de pequeño tamaño, bien por economizar la materia prima de mejor calidad; por ejemplo, en el nivel II se ha recuperado un núcleo cuya última extracción en forma de lasca presenta un negativo de $17 \mathrm{~mm}$ de longitud y 10,5 $\mathrm{mm}$ de anchura. La gestión de la talla propiamente de lascas también se ha documentado a partir de núcleos de tipo globuloso, sin un esquema de reducción más allá del marcado por la propia morfología del núcleo y los negativos de las extracciones previas.

El total de soportes es de 814, con un patrón homogéneo en todos los niveles: las lascas son el soporte más numeroso seguidas de las laminitas, lascas laminares y láminas, además de una muestra reducida de astillas. El objetivo de la talla es la obtención de soportes laminares, dando como resultado un índice laminar del $50 \%$ en el nivel III y de $38-37 \%$ en II y IV. Los soportes de mayor envergadura, como las láminas, no son muy numerosos debido al escaso desarrollo métrico de algunos nódulos, produciéndose en su lugar lascas laminares (soportes de tipometría de lascas con estructura laminar). En la tipometría del conjunto laminar se observa una continuidad en la relación longitud y anchura de las láminas y laminitas. Morfológicamente los productos laminares tienen secciones triangulares que prevalecen sobre las trapezoidales y las escasas poligonales; predominan los perfiles ligeramente cóncavos y, a continuación, los torcidos y planos. Para su producción se emplean generalmente percutores blandos minerales, excepto en las laminitas del nivel II en las que se documenta más la percusión blanda orgánica. El uso de percutores duros en los soportes laminares es esporádico y solo se observa en algunas lascas laminares. La preparación de los talones es habitual, siendo la abrasión la más repetida, mientras que el adelgazamiento es algo más ocasional y en piezas laminares de mayor tamaño. Con independencia del soporte laminar, los talones lisos son dominantes, seguidos por los lineales en lascas laminares y laminitas, y diedros en láminas. El resto de tipos de talón presentan una frecuencia anecdótica. Por otro lado, en las lascas, al igual que el grupo laminar, el percutor más usado es el blando mineral, aunque en este soporte la percusión dura es 


\begin{tabular}{|c|c|c|c|c|}
\hline & \multicolumn{3}{|c|}{ Gravetiense } & \multirow{2}{*}{$\frac{\text { S-G }}{I}$} \\
\hline & IV & III* & II & \\
\hline Raspador & 5 & 4 & 2 & 16 \\
\hline Compuesto & 1 & & & 3 \\
\hline Perforadores & & & 1 & 4 \\
\hline Buriles & 6 & 3 & 7 & 15 \\
\hline Dorsos & 6 & 2 & 12 & 8 \\
\hline Truncadura & 1 & & 4 & 6 \\
\hline Piezas retocadas & 4 & 3 & 9 & 17 \\
\hline Solutrense & & & & 2 \\
\hline Muescas y denticulados & & 1 & 2 & 2 \\
\hline Piezas astilladas & 3 & & 3 & 11 \\
\hline Raederas & 1 & & & \\
\hline Raclette & & & 1 & \\
\hline Microlaminar & 9 & 3 & 22 & 34 \\
\hline Varios & 3 & & 4 & 10 \\
\hline Retoques de uso & 7 & 1 & 14 & 26 \\
\hline Total & 46 & 17 & 81 & 128 \\
\hline \multicolumn{5}{|l|}{ Solutrense } \\
\hline Punta escotada & & & 2 & 2 \\
\hline \multicolumn{5}{|l|}{ Puntas de dorso } \\
\hline Punta de La Gravette & 2 & & & 1 \\
\hline Punta de Vachons & & & 1 & \\
\hline Microgravette & 1 & 2 & 4 & 3 \\
\hline Punta tipo Cendres & & & 1 & \\
\hline \multicolumn{5}{|l|}{ Microlaminar } \\
\hline Trucadas, triángulos y rec. & & & 2 & 1 \\
\hline Dorso apuntado & 3 & 1 & 9 & 9 \\
\hline Dorsos & 2 & & & 8 \\
\hline Micro laminita de dorso & 1 & 2 & & \\
\hline Finos retoques directos & 3 & & 4 & 10 \\
\hline Laminita con muesca & & & & 2 \\
\hline Laminita denticulada & & & 1 & \\
\hline Dufour & & & & 1 \\
\hline Retoques inversos & & & 2 & 3 \\
\hline
\end{tabular}

Figura 5: Industria lítica retocada por niveles. Detalle a grupos: Solutrense, dorsos y microlaminar. * Incluye capas de transición II-III y III-IV

más frecuente. Respecto a la morfología de los talones, la lisa es la principal, seguida de la cortical, diedra y lineal en proporciones similares. Algunas lascas presentan abrasiones y adelgazamientos.

Del total de soportes, 144 presentan retoque $(17,7 \%)$ y su distribución por niveles está en consonancia con la densidad de materiales (Figs. 5 y 6 ). La totalidad del material retocado está confeccionado sobre piezas de sílex, primando aquellas variedades de mejor calidad. Respecto a los útiles para actividades domésticas, el número de buriles es muy superior al de los raspadores en el nivel II; en los niveles IV y III su cifra es prácticamente idéntica. Morfológicamente los raspadores sobre lasca y sobre lasca retocada son los más abundantes. Algunos se configuran sobre productos de mantenimiento de núcleo, como los flancos, debido a su mayor robustez. Los tipos de buril más repetidos son el diedro de ángulo y sobre truncadura. Con menor frecuencia se documentan truncaduras, muescas, denticulados y piezas astilladas, estas últimas, empleadas a modo de cuña para cortar madera o hueso (de la Peña, 2011; Vadillo et al., e. p.). Otra característica para destacar es el bajo índice de piezas con retoques en uno o dos bordes, a diferencia de las piezas con retoques de uso bastante bien representadas.

Por otro lado, los proyectiles se integran fundamentalmente en el grupo microlaminar, lógico en un conjunto en el que las laminitas superan ampliamente a las láminas. Ahora bien, también se documentan proyectiles de dorso de mayor tamaño como puntas de La Gravette, de Vachons y microgravettes, o sin dorso, como una punta tipo Cendres en el nivel II. Las laminitas de dorso apuntado son los proyectiles microlaminares más abundantes, seguidas de las de dorso, que suelen corresponder a fragmentos mediales y que posiblemente, en algún caso, correspondieran a una pieza apuntada. En los niveles IV y III destacan por su singularidad tres microlaminitas de dorso con anchuras menores a $2,5 \mathrm{~mm}$, similares a las localizadas en los niveles XVIA y XVIB de la Cova de les Cendres (Villaverde et al., 2019).

Los grupos tipológicos recuperados en estos niveles (IV al II) se corresponden claramente con la tipología gravetiense documentada en otros yacimientos de la zona como la Cova de les Cendres (Villaverde et al., 2019) o la Cova de les Malladetes (Villaverde et al., 2021).

\subsection{Nivel I. AsPeCtos TECNOLÓGICOS Y TIPOLÓGICOS}

El conjunto lítico del nivel se compone de 2414 restos, de ellos el $60 \%$ son desechos de talla, incluyendo esquirlas (Fig. 4). Teniendo en cuenta las limitaciones del material, la presencia de soportes plenamente corticales o con superficie dorsal ampliamente cortical indica que la cadena operativa se desarrollaría al completo en el yacimiento. No obstante, como en los niveles subyacentes, algunos nódulos pudieron ser aportados al abrigo con un testeo previo. Los soportes de decalotado $(0,7 \%)$ fundamentalmente son lascas y algunas lascas laminares. Las piezas de segundo orden están bien representadas desde porcentajes superiores al $50 \%$ de córtex, la cuales se incluyen en la fase de inicio de explotación y preparación de las superficies. Los soportes laminares con alto índice cortical son esporádicos, la mayoría tienen menos del $20 \%$ de córtex y se relacionan con la recuperación de zonas corticales residuales en los núcleos, señal de la poca atención a la eliminación total del córtex en los núcleos más allá de la configuración necesaria. 


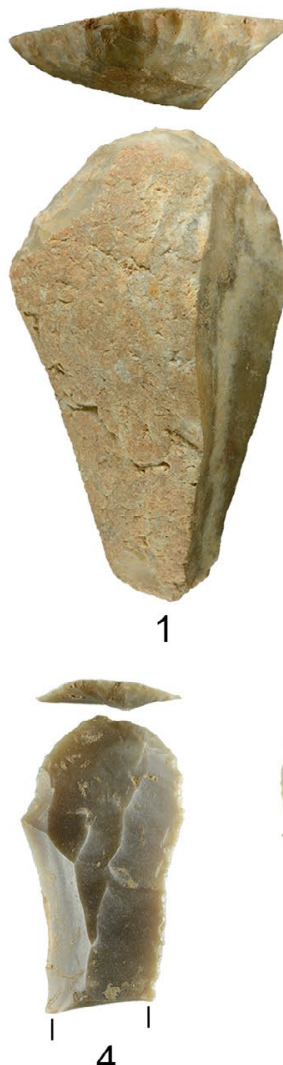

4

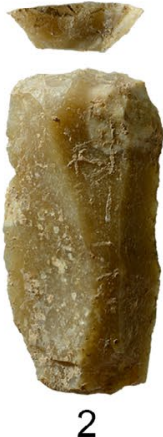

2
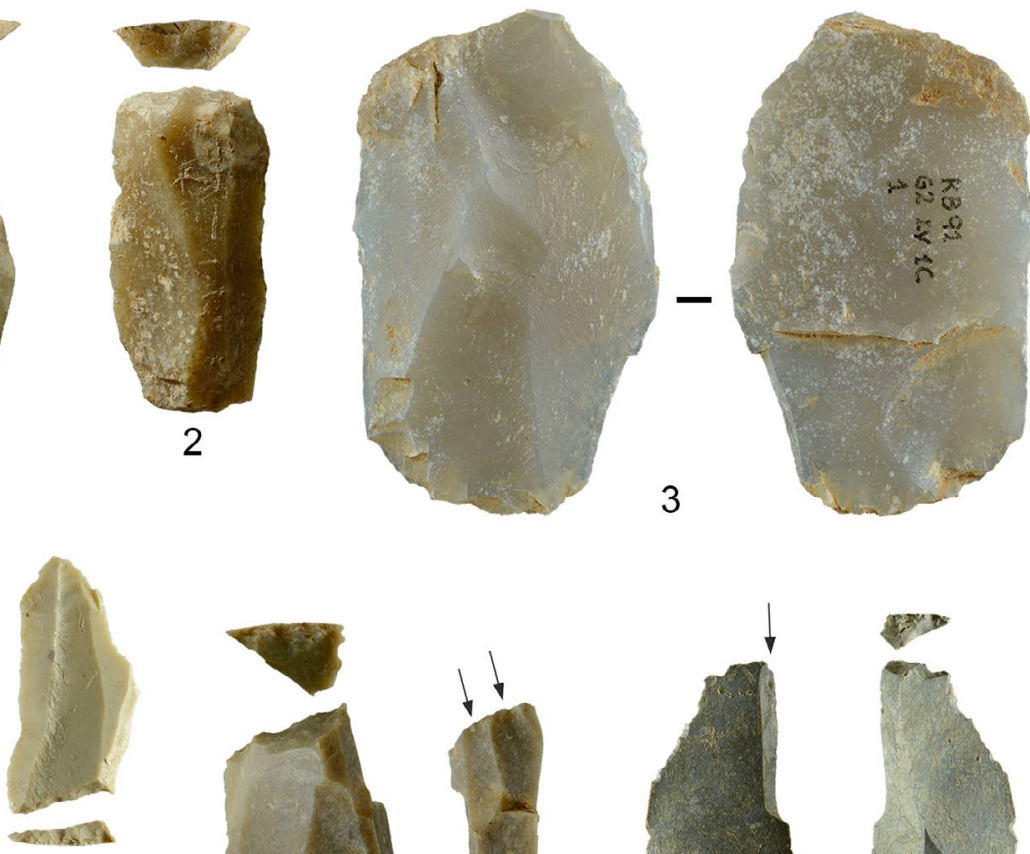

5

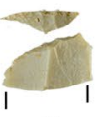

6

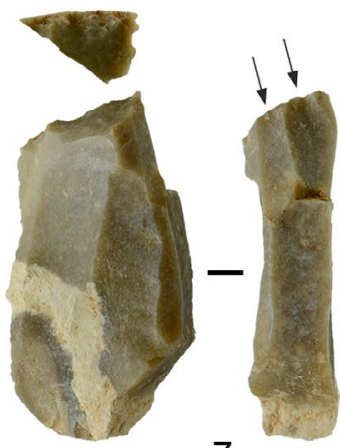

7

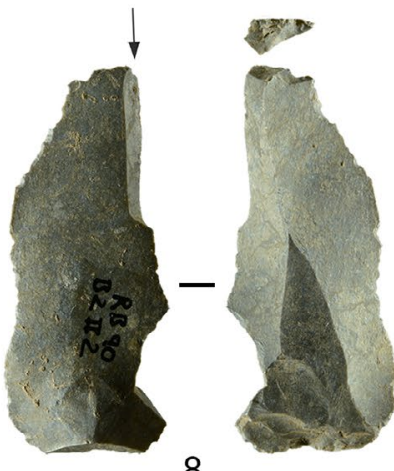

8

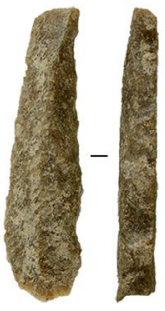

9

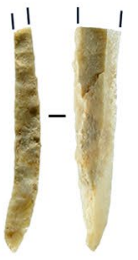

15
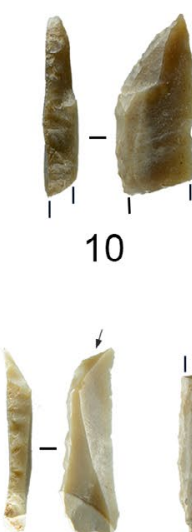

16

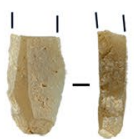

22
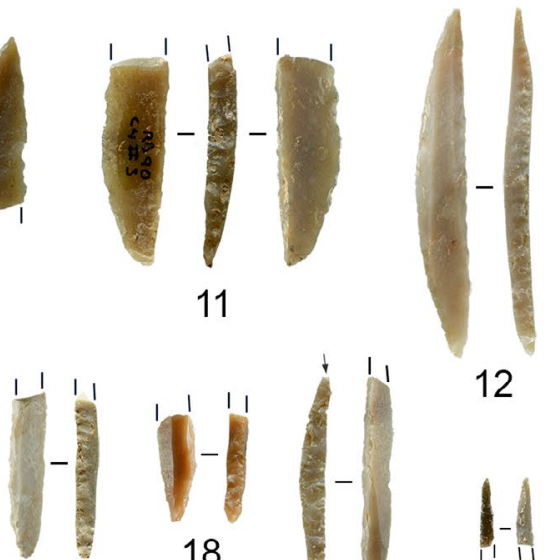

17

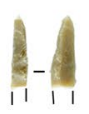

23

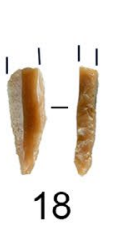

18

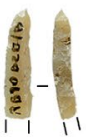

24

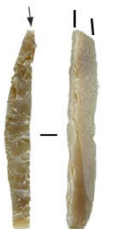

19

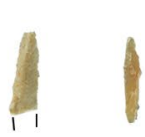

25

26
12

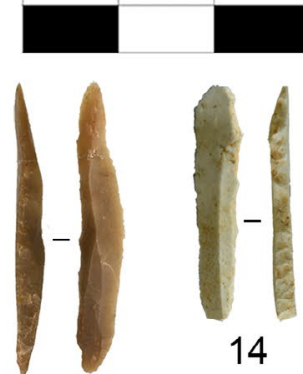

13

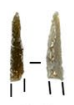

20
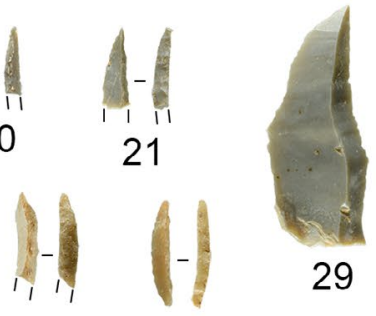

28

Figura 6: Material lítico retocado de los niveles gravetienses (IV a II): Raspadores (1-2, 4), pieza astillada (3), truncaduras (5-6), buriles (7-8), puntas de La Gravette (9-10), punta de Vachons (11), microgravettes (12-15), laminitas de dorso apuntado (19, 21, 23-25, 27), laminita de dorso $(16-18,22)$, microlaminita de dorso $(20,26,28)$ y punta tipo Cendres $(29)$

Los núcleos recuperados y los productos de mantenimiento laminar permiten identificar diversos esquemas de talla para la obtención de soportes laminares y lascas. De producción laminar se han recuperado 13 núcleos -12 prismáticos y 1 carenado-. Mayoritariamente son núcleos de laminitas, aunque también se recuperaron de láminas, estos últimos con una menor intensidad de explotación y, por tanto, menor rendimiento de la materia prima. La dirección de la talla básicamente es unipolar con un plano de explotación, incorporando en algunos casos un segundo plano secante. La talla bipolar es mucho menos frecuente y se documenta fundamentalmente a partir de negativos de los soportes. En líneas generales, los núcleos fueron escasamente preparados 

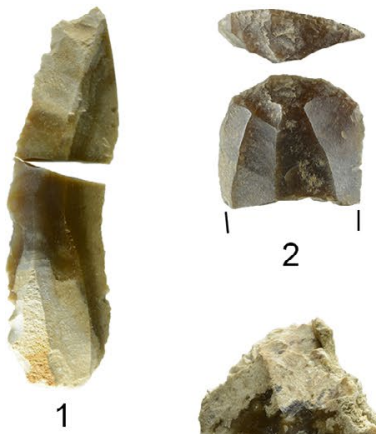

2

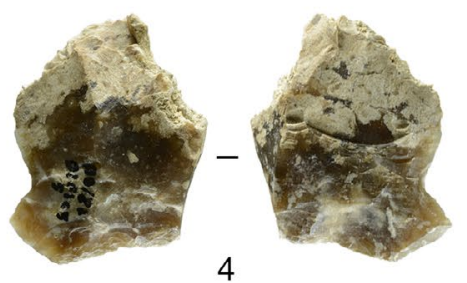

4
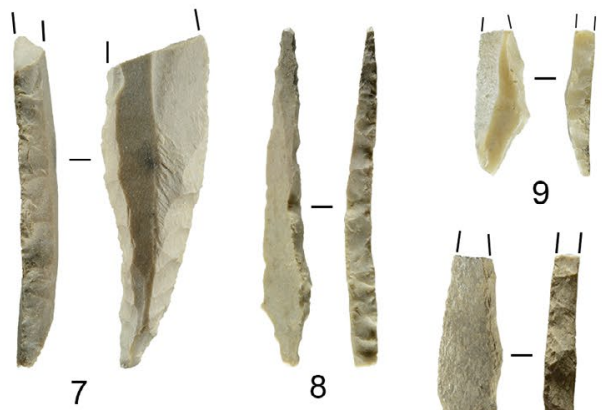

9

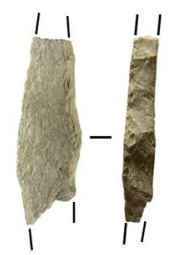

14
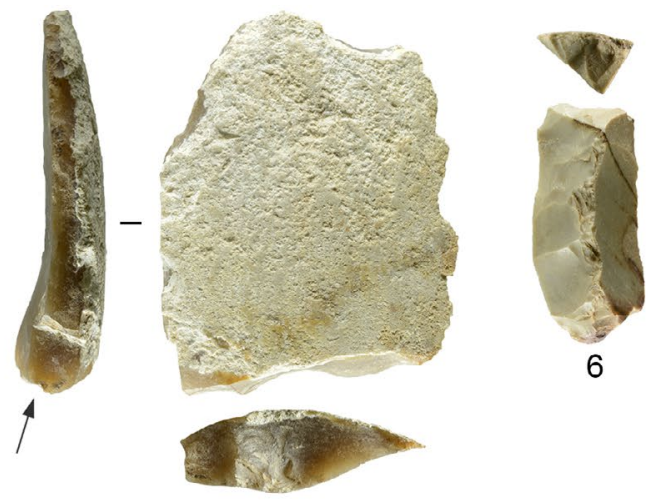

5

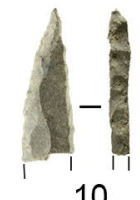

10

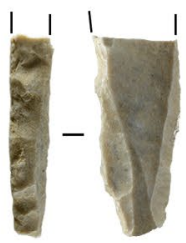

15

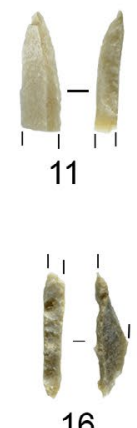

16
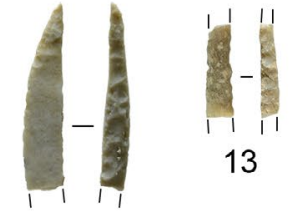

13

12

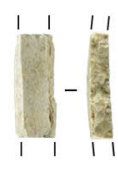

17

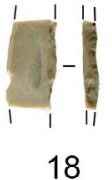

18

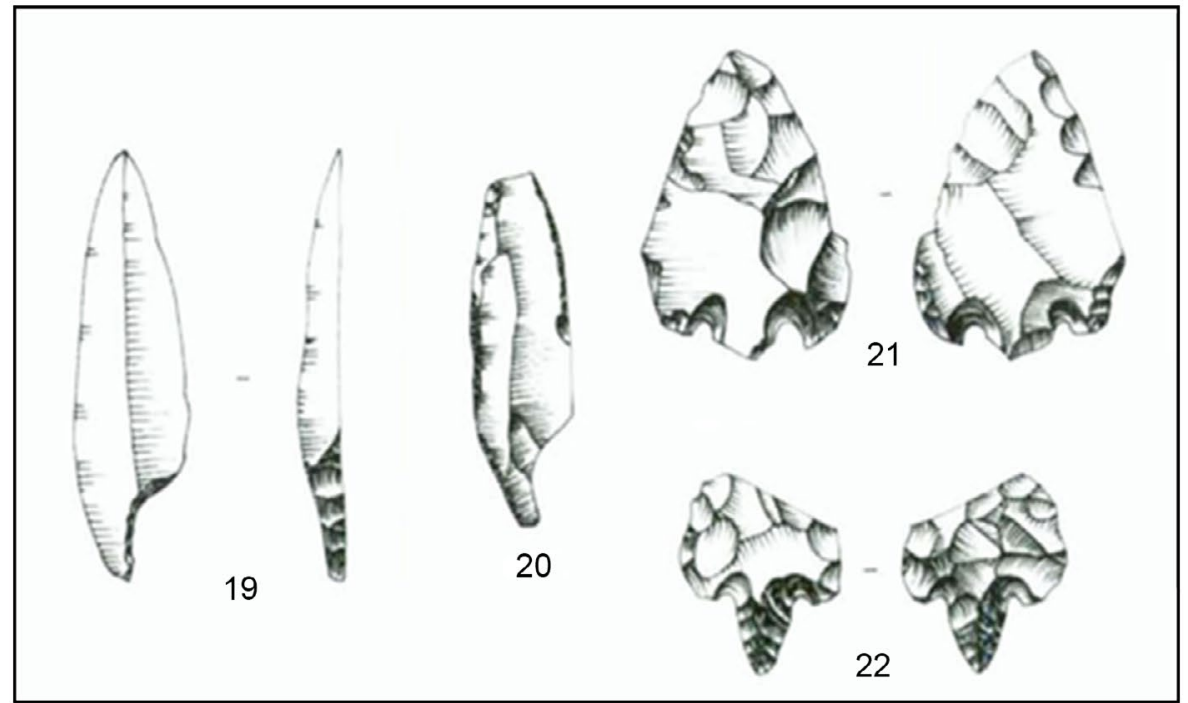

Figura 7: Material lítico retocado del nivel solútreo-gravetiense (I): Lámina retocada (1), frentes de raspador (2-3), pieza astillada (4), buril (5), truncadura (6), puntas escotadas (7-8), laminitas de dorso $(9,13,16-18)$, laminitas de dorso apuntado (10-12), microgravette (14), punta de La Gravette (15). Piezas (19-22) procedentes de la colección clandestina depositada en el Museo Arqueológico Municipal de Novelda (tomado de Menargues y Navarro, 2001): Puntas escotadas (19-20) y puntas de aletas y pedúnculo (21-22)

para el inicio de explotación, y aprovechan las aristas creadas por los meplats de los núcleos. La preparación más compleja es reducida, no se ha recuperado ninguna cresta y solo cinco semicrestas. El mantenimiento de los núcleos es bastante recurrente con: 1) semitabletas para la recuperación parcial de los planos de percusión y, de forma menos invasiva, a partir de la extracción de cornisas; 2) aristas para la rectificación de zonas concretas de la superficie de debitado; 3 ) flancos para la rectificación de toda la superficie. De nuevo, encontramos dos tipos de flancos, los más numerosos son aquellos que recuperan la curvatura manteniendo el plano de percusión, y mucho menos frecuentes son aquellos que rectifican desde un plano oblicuo o transversal respecto al original y, en consecuencia, cambian la dirección de la talla. Respecto a la producción de lascas se ha podido 
determinar, al menos, dos gestiones de la talla diferentes: la más numerosa es la de tipo globuloso y, en segundo lugar, la de tipo discoide. Además, se ha documentado la producción de astillas a partir de un núcleo para tal fin y no solo mediante la presencia de astillas.

Los soportes totales ascienden a 837, las lascas son el soporte más representado, seguido de las laminitas, lascas laminares, láminas y astillas. El grupo laminar supone el $45 \%$ de los soportes, y se caracteriza por la continuidad métrica en la distribución de anchuras, con secciones mayoritariamente triangulares y perfiles cóncavos y torcidos en proporción similar. Para su producción se emplea de manera casi exclusiva la percusión blanda, en valores similares se documenta el uso de percutores orgánicos, minerales y el grupo de piezas con signos de percutor blando que no ha podido ser determinado como mineral u orgánica. Por su parte, la morfología de talón más recurrente es lisa, seguida de lineal. Un aspecto a destacar es la buena representación de preparación mediante el empleo de la abrasión. En lo que respecta a las lascas hay un dominio de percutores blandos, siendo el menos frecuente el orgánico, pero también se emplean percutores duros. Los talones lisos dominan seguidos en mucha menor proporción por diedros, lineales y corticales, entre otros.

Respecto al utillaje retocado, se contabilizan 128 piezas, lo que supone que el $15 \%$ de los soportes presenta retoques y todos fueron realizados en sílex (Figs. 5 y 7). El número de raspadores y buriles es prácticamente idéntico, documentándose tres útiles compuestos de raspadores-buril. Las piezas astilladas, cuya presencia en los niveles inferiores es esporádica, en este nivel suponen 11 ejemplares. Otros útiles menos numerosos son las truncaduras, muescas y denticulados. Además, hay un nutrido conjunto de piezas con retoques en uno o dos bordes, entre las que se incluye dos lascas con retoques planos. El grupo con mayor representación es el microlaminar $(27 \%)$, con un número reseñable de laminitas con finos retoques tanto directos como inversos. 17 piezas microlaminares se corresponden con proyectiles de dorso inferiores a $5 \mathrm{~mm}$ de anchura, 9 de ellos apuntados. También se documentan una punta de La Gravette y tres microgravettes. A este considerable conjunto de proyectiles de dorso se añaden dos puntas escotadas de tipología algo incierta. Por su interés para la adscripción cultural del nivel nos detendremos en su comentario. La primera, consiste en un fragmento proximal realizado sobre lámina, en el que la escotadura, de poca concavidad, se sitúa en el lado izquierdo; en ese mismo lado está el retoque abrupto, mientras que en el lado derecho un retoque simple con tendencia a abrupto modifica ligeramente la anchura de la pieza en la zona opuesta a la escotadura (Fig. 7: n. ${ }^{\circ}$ 7). La segunda es una pieza microlaminar, que presenta una escotadura también poco marcada, situada en el lado derecho, que se configura mediante retoque abrupto en el mismo lado (Fig. 7: n. ${ }^{\circ}$ 8). Las dos piezas se separan del morfotipo característico de punta escotada tal y como se documenta habitualmente en los yacimientos en los que este tipo de piezas aparecen ampliamente documentadas. Basta recordar que lo habitual en este tipo de puntas es que la escotadura se sitúe en la parte proximal derecha y el retoque abrupto se extienda por el lado opuesto, con algunos casos de complemento mediante retoque inverso simple en la zona que corresponde a la escotadura. El número de escotaduras en el lado izquierdo asciende, por ejemplo, a tan solo un $3,8 \%$ en el Solutrense evolucionado de Parpalló (25 de 655 piezas) (Villaverde y Peña, 1981). Este cómputo engloba los materiales procedentes de los niveles adscritos al Solutrense superior (de 5,75 a 5,25 m) y al Solútreo-gravetiense (de 4,75 a 3,75 m).

Como se ha indicado anteriormente, el nivel I no dispone de datación por lo que su adscripción cultural solo es posible en base a criterios tipológicos. Si atendemos al utillaje que podemos calificar de diagnóstico, éste lo conforma el nutrido grupo de elementos de dorso, las dos puntas escotadas y dos piezas con retoque plano. Aún siendo conscientes de las limitaciones de este tipo de adscripciones, planteamos la posibilidad de que este nivel corresponda al Solútreo-gravetiense, una fase detectada también en los materiales procedentes de excavaciones clandestinas depositados en el Museu Arqueologic Municipal de Novelda. Las dos puntas escotadas recuperadas en las excavaciones clandestinas resultan de morfología clásica y redundan en la idea de que la parte superior de la secuencia pueda corresponder al Solútreo-gravetiense, especialmente al asociarse a dos puntas de pedúnculo y aletas (Fig. 7: n. ${ }^{\circ}$ 21-24).

\section{CRONOLOGÍA}

La revisión de los materiales antracológicos de los niveles IV al II ha permitido obtener 15 nuevas dataciones mediante AMS y pretratamiento AAA (Fig. 8). Los resultados de la serie evidencian la existencia de ciertas alteraciones de carácter tafonómico. Las muestras de Juniperus sp. han dado resultados coherentes con el material lítico asociado, salvo en una ocasión (Beta - 56551). Además, una muestra de Ephedra sp. ha resultado de cronología gravetiense. Cinco muestras de diversos taxones cálidos resultaron claramente anómalas por su cronología medieval y moderna. Más allá de una reducida parte del registro antracológico, no se ha detectado materiales incoherentes con la atribución cultural de los niveles. Este hecho puede ser debido a varios factores: a) percolaciones de material ligero en zonas de concentración de bloques por desprendimientos cenitales; b) la escasa variación de la matriz fina de los distintos niveles; c) la existencia de fuertes variaciones laterales en la potencia de los estratos; y d) fundamentalmente, la bioturbación asociada a madrigueras de lagomorfos, tal vez no siempre detectadas en el proceso de excavación.

Creemos conveniente hacer un análisis crítico de las dataciones cuyos resultados han sido problemáticos y su posible explicación. Todas las dataciones obtenidas 


\begin{tabular}{|c|c|c|c|c|c|c|c|c|}
\hline Año & Nivel & Capa & Cuadro & Lab \# & Taxón & ${ }^{14}$ C BP & $\begin{array}{c}\text { Cal BP } \\
\text { IntCal13 }\end{array}$ & Observaciones \\
\hline 1990 & II & AHogar & F.3 & Beta-565510 & Juniperus sp. & $23620+/-90$ & $27901-27556$ & \\
\hline 1990 & II & AHogar & F.3 & Beta-565511 & Juniperus sp. & $21190+/-80$ & $25748-25284$ & \\
\hline 1990 & II & 1A & B.2 & Beta-565512 & Juniperus sp. & $22270+/-90$ & $26886-26174$ & \\
\hline 1990 & II & 2 & E.4 & Beta-565513 & Juniperus sp. & $25740+/-100$ & $30340-29529$ & \\
\hline 1990 & II & 2 & E.4 & Beta-565514 & Ficus carica & $103.16+/-0.39$ pMC & & Intrusión \\
\hline 1990 & II & 3 & E.4 & Beta-565515 & Pistacia sp. & $900+/-30$ & & Intrusión \\
\hline 1990 & II & 3 & E.4 & Beta-565516 & Ephedra sp. & $200+/-30$ & & Intrusión \\
\hline 1990 & II & 3 & E.4 & Beta-565517 & Juniperus sp. & $860+/-30$ & & Intrusión \\
\hline 1990 & III-IV & & F.4 & Beta-565518 & Juniperus sp. & $25890+/-100$ & $30552-29701$ & \\
\hline 1990 & IV & 1 & C.3 & Beta-565519 & Juniperus sp. & $21770+/-80$ & $26161-25835$ & \\
\hline 1990 & IV & 1 & D.4 & Beta-565520 & Ephedra sp. & $21450+/-90$ & $25950-25577$ & \\
\hline 1991 & IV & 2 & E.4 & Beta-565521 & Juniperus sp. & $21890+/-80$ & $26325-25905$ & \\
\hline 1991 & IV & 3 & C.4 & Beta-565522 & Juniperus sp. & $24780+/-90$ & $29050-28554$ & \\
\hline 1991 & IV & 4 & C.3 & Beta-565523 & Pistacia sp. & $900+/-30$ & & Intrusión \\
\hline 1991 & IV & 4 & F.2 & Beta-565524 & Juniperus sp. & $24500+/-90$ & $28780-28300$ & \\
\hline
\end{tabular}

Figura 8: Dataciones radiocarbono procedentes de los niveles IV al II (incluye resultados de muestras de taxones intrusivos en los niveles paleolíticos). Cronología calibrada a partir de la curva de calibración atmosférica r:5 IntCal13 (Reimer et al., 2013) y uso de software OxCal v4.4.2. (C) Bronk Ramsey 2020

en el cuadro E4 han resultado incoherentes, dos fechas sobre Juniperus sp. de cronología paleolítica muestran inversión cronológica entre ellas (Beta - 565513 y Beta - 565521) y otra junto a tres de especies cálidas (Ficus carica, Pistacia sp. y Ephedra sp.) que son de época histórica. El resultado de Juniperus sp. obtenido en el nivel IV, cuadro C3, (Beta - 565519) es llamativamente joven en comparación con las del resto del nivel. En el cuadro contiguo se detectó una madriguera que posiblemente afectase al cuadro $\mathrm{C} 3$ y no fuera percibida durante su levantamiento. La muestra de Ephedra sp. (Beta - 565520), al igual que la anterior, para el nivel IV da un resultado joven. Esta muestra debe proceder de uno de los niveles superiores del Gravetiense y su anomalía vuelve a remitir a las explicaciones antes enunciadas. Finalmente, la muestra de Juniperus sp. del nivel III (capa III-IV) es la que ha aportado una cronología más antigua a la secuencia (Beta - 565518: $25.890 \pm 100 \mathrm{BP})$, la problemática que presenta el nivel nos obliga a valorarla con extrema cautela.

Otro aspecto que debemos tener en cuenta es que las dos nuevas dataciones obtenidas para carbones recuperados en el proceso de excavación del hogar del nivel II, documentado en la campaña de 1990, contradicen claramente la fecha que hasta ahora disponíamos para esta estructura de combustión (Ly - 5219: 17.360 180 BP) y que en su día permitió relacionar el nivel con el Solútreo-gravetiense (Soler et al., 1990). El hecho de que esta fecha se obtuviera a partir de un agregado de carbones de Juniperus sp. puede constituir la explicación de esta discordancia, ya que podría englobar algún carbón de cronología más reciente y afectar al resultado.
Las nuevas dataciones avalan esa interpretación porque una muestra de Juniperus sp. (Beta - 565517: 860 \pm 30 BP) del nivel II ha ofrecido una cronología medieval. La otra posibilidad, que el hogar corresponda en realidad al nivel I, entra en contradicción con los resultados proporcionados por las dos dataciones obtenidas en carbones individuales de Juniperus sp. para esta misma estructura que ahora presentamos (Beta - 565510:

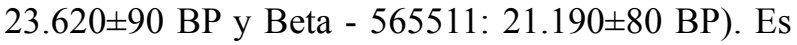
oportuno recordar que en la publicación de la fecha y la atribución cultural del nivel II intervino de manera decisiva el conocimiento de que en el abrigo existía un lote de materiales de clara adscripción al Solútreogravetiense, con presencia de dos puntas escotadas y dos puntas de pedúnculo y aletas, además de la existencia de dos puntas escotadas entre los materiales recuperados en las campañas aquí analizadas, pero localizadas en el nivel I. Por tanto, si consideramos el resto de las dataciones del nivel y el estudio detallado del material lítico, no parece forzado pensar que el nivel II pueda encuadrarse en el Gravetiense, y que el Solútreo-gravetiense quede limitado al nivel I, del que no hemos podido obtener ninguna datación.

Los resultados de las dataciones desaconsejan plantear el rango cronológico en el que se circunscribe cada uno de los niveles. Sin embargo, una vez descartadas las dataciones de época histórica, el marco cronológico en el que se sitúa el resto de fechas con independencia de su inversión estratigráfica- es el del tecnocomplejo Gravetiense en la región central mediterránea ibérica (Villaverde, Martínez-Alfaro y Bel, 2021). Para documentar el marco temporal de 
las ocupaciones gravetienses, que engloban los niveles IV al II, se ha construido un modelo cronológico bayesiano. El modelo presenta un elevado índice de concordancia con un $\mathrm{A}_{\text {model }}$ de 103,1, sitúa el comienzo de la ocupación gravetiense hacia el 30.500 cal BP y su final hacia 25.300 cal BP, con unos límites entre 31.80029.700 y $25.800-23.800$ cal BP. Finalmente, para cerrar el apartado cronológico, sin olvidar la mencionada problemática de algunos resultados de la serie y a modo tentativo, el nivel II podría situarse cronológicamente

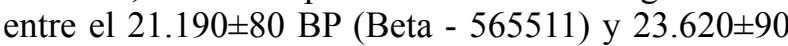
BP (Beta - 565511). Mientras que las ocupaciones del nivel IV pudieron darse entre el 24.500 $\pm 90 \mathrm{BP}$ (Beta - 565524) y el 24.780 90 BP (Beta - 565522). Una vez calibrada, la cronología es la siguiente: nivel IV 29.050-28.300 cal BP y nivel II 27.900-25.280 cal BP.

\section{REGISTRO VEGETAL}

En el conjunto de restos vegetales hemos identificado la siguiente lista de plantas: Juniperus sp. (enebros en sentido amplio), Juniperus sp. endocarpo muy fragmentado, Pinus nigra-sylvestris (pino salgareño o albar), Artemisia sp. (boja), Ephedra sp. (belcho), Lamiaceae, Fabaceae, Rhamnus-Phillyrea (aladierno o aladierna), Cistus sp. (jara), Monocotiledónea, Fraxinus sp. (fresno), Corteza, Angiosperma, Pinus halepensis (pino carrasco), Ficus carica (higuera), Olea europea (acebuche) y Pistacia sp. (lentisco, cornicabra).

\subsection{CARBÓN, RADIOCARBONO Y TAFONOMÍA}

Uno de los objetivos planteados para la serie cronológica (Fig. 8) era respaldar o descartar las hipótesis de los refugios en Iberia durante el último glacial. Como se ha visto en el apartado cronológico, las muestras de especies cálidas tienen fundamentalmente un origen reciente e intrusivo. De los dos carbones de Ephedra sp. datados, uno es paleolítico y el otro es moderno, lo que demuestra que este taxón es local y bien adaptado al clima regional y que tiene una gran amplitud de tolerancia térmica porque pervivió durante el último glacial en las zonas áridas de Iberia. Una de las muestras de
Juniperus sp. ha resultado moderna, sin embargo, el resto han dado cronología paleolítica y son coherentes con el material lítico asociado. De Pistacia sp. se ha fechado un carbón recuperado en el nivel IV y otro en el nivel II y la datación es igual en ambos casos, medieval (1039 - 1210 cal AD). El carbón de Ficus carica es del siglo XX y, de forma similar a los de Pistacia sp., su presencia debe responder a penetraciones del nivel superficial por agentes bióticos como hormigas o galerías de micromamíferos que no se detectaron durante la excavación.

Estos resultados son interesantes y necesarios para demostrar las alteraciones post-deposicionales y realizar interpretaciones coherentes desde el punto de vista ecológico y paleoclimático a partir de los restos arqueobotánicos. Así excluimos del diagrama antracológico: Pistacia sp, Ficus carica, Olea europea y Pinus halepensis. Este último lo descartamos porque, aunque no lo hemos datado, sí lo hemos hecho en otros muchos yacimientos ibéricos y siempre da unas fechas holocenas, así que aquí lo consideramos, también, intrusión del nivel superficial.

\subsection{FLORA, CLIMA Y ACTIVIDAD HUMANA}

Los carbones paleolíticos analizados son 1823, una vez excluidas la fracción intrusiva de 84 carbones históricos. 118 carbones estaban concentrados en el hogar situado en el cuadro F3 del nivel II, estando el resto dispersos por los distintos niveles arqueológicos.

La estructura de combustión del nivel II era un hogar plano con la base de tierra apelmazada, piedras planas y cubierto de cenizas, algún carbón, restos de fauna y tierra. Los 118 carbones recuperados en este hogar eran de Juniperus sp., lo que nos indica una recolección sistemática de leña de enebros para alimentar el fuego. El endocarpo de enebro identificado, puede ser explicado por su introducción en el abrigo en las ramas de la leña.

Los resultados cualitativos y cuantitativos se pueden observar en el diagrama antracológico (Fig. 9). Los carbones de Juniperus sp. superan el 90\% del carbón identificado. Las especies de este género solo se pueden identificar por la morfología de sus semillas, pero

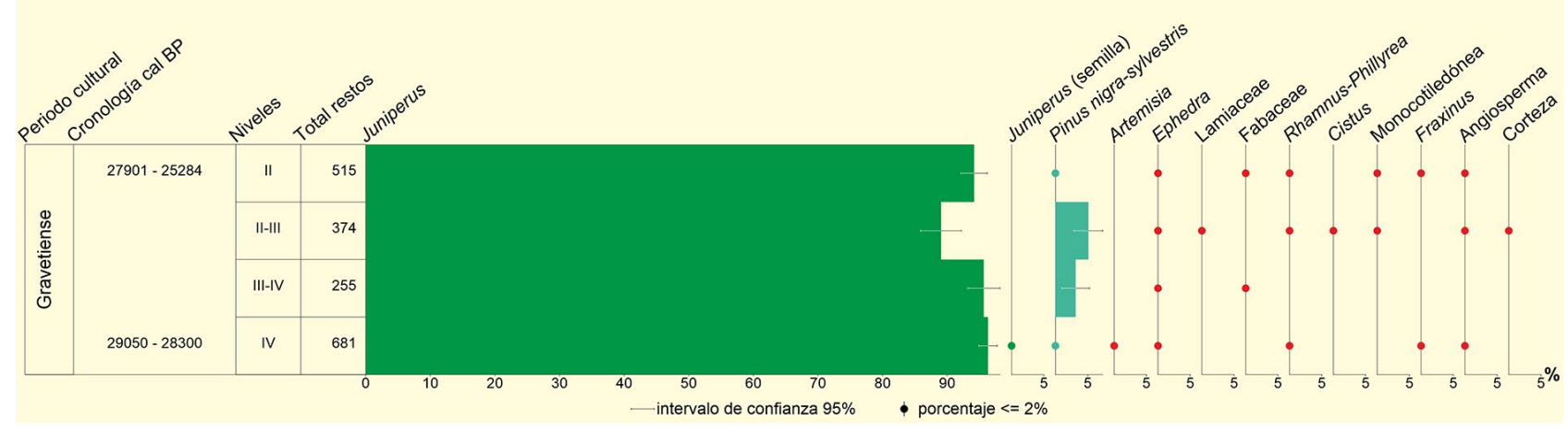

Figura 9: Diagrama antracológico de los niveles gravetienses (IV-II) 

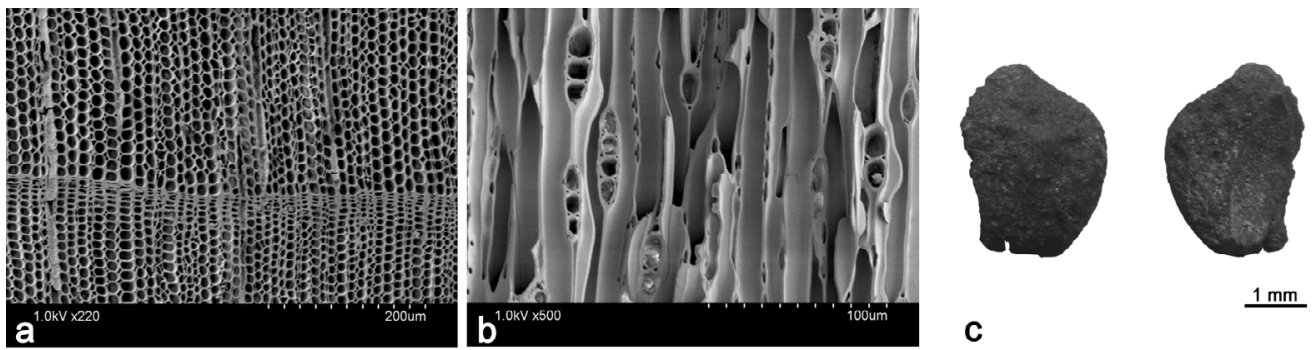

C
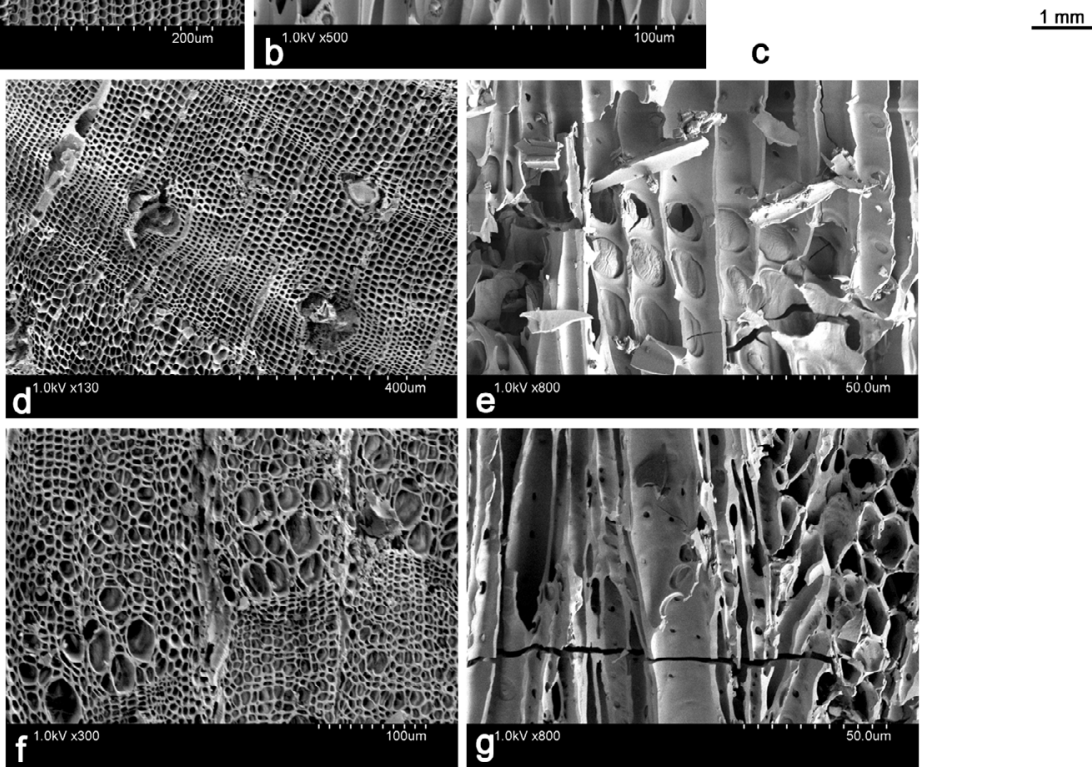

Figura 10: Microfotografías de vegetales del nivel IV. Juniperus sp. (a, b, c). Pinus nigra-sylvestris (d, e) y Ephedra sp. (f, g). Plano transversal de la madera: a x200; d x130 y f x500. Plano tangencial: b x500. Plano radial: e y g x800. c: fragmento de endocarpo

desgraciadamente solo hay una y su estado de conservación impide conocer a qué especie pertenece. Es probable que haya más de una especie, como ocurre en el Gravetiense medio (nivel XVIA) de la Cova de les Cendres, donde conviven los Juniperus de ecología fría J. communis (enebro común), J. sabina (sabina rastrera) y $J$. thurifera (sabina albar) con las más cálidas como $J$. oxycedrus (cade) y $J$. phoenicea (sabina negral) (Martínez-Varea, 2020).

Pinus nigra-sylvestris está presente en todos los niveles, aunque con porcentajes inferiores al $5 \%$. Con la anatomía de la madera no podemos discriminar si se trata de $P$. nigra (pino salgareño) o $P$. sylvestris (pino albar). En todo caso, ambas especies tienen una ecología fría, en la actualidad viven en la Comunidad Valenciana por encima de los 1800 metros de altitud en las montañas de Peñagolosa, donde la temperatura media anual está en torno a los $1{ }^{\circ} \mathrm{C}$ y la precipitación media anual supera los $600 \mathrm{~mm}$. Estos pinos no podrían vivir actualmente en la Serra de Crevillent, donde la temperatura media es de $17,9{ }^{\circ} \mathrm{C}$ y la lluvia no llega a los $300 \mathrm{~mm}$. Así pues, la presencia de Pinus nigra-sylvestris en todos los niveles de la Ratlla del Bubo indican un clima mucho más frío que el actual, del orden de $7-8^{\circ} \mathrm{C}$ menos de media anual. La poca proporción de carbones de estos pinos puede indicar que no formaran grandes masas debido a la aridez de la zona y que los árboles dominantes serían los enebros, mucho mejor adaptados a las condiciones áridas y frías de Iberia, tanto en el Paleolítico como en la actualidad.
La ausencia total de carrascas también indica la aridez de la zona.

El resto de la flora identificada son matas o arbustos heliófilos y bien adaptados a la sequía mediterránea: Artemisia sp. (boja), Ephedra sp. (belcho), Lamiaceae, Fabaceae, Rhamnus-Phillyrea (aladierno o aladierna) y Cistus sp. (jara). Se ha identificado una monocotiledónea que por su estructura anatómica parece ser esparto, lo que está en concordancia con la aridez de la zona. Se han identificado 8 fragmentos de carbón de Fraxinus sp. (fresno), árboles que viven en cursos de agua o en umbrías donde hay mayor humedad. Además, se han encontrado fragmentos de corteza de ramas y algunos carbones de angiospermas que no hemos podido identificar.

En definitiva, el análisis de los carbones de la Ratlla del Bubo (Fig. 10) indica que la actividad de leñateo estaba orientada a los enebros y en mucha menor proporción a los pinos, arbustos y matas de mediano o pequeño tamaño. Todas las plantas identificadas arden bien, a condición de que la madera esté seca. Además, la quema de enebros y boja desprende un agradable aroma y podría incluso servir de repelente de insectos como hacían ciertos grupos nativos de Norteamérica.

Los paisajes de la Serra de Crevillent serían enebrales fríos y áridos similares a los identificados en el paleolítico del Abrigo de La Boja (Mula, Murcia) (Badal et al., 2019). La poca cantidad de leña quemada de los pinos (P. nigra-sylvestris) avala la aridez de la zona, que es estructural debido a la situación 
geográfica poco propicia a los vientos húmedos del Mediterráneo. En contraste, la Marina Alta es y fue mucho más húmeda, porque en los niveles gravetienses de la Cova de les Cendres, las proporciones de leña de pinos ( $P$. nigra-sylvestris) dominan los espectros antracológicos y además se han identificado las cinco especies de enebros y una rica y variada flora (Villaverde et al., 2019).

\section{FAUNA}

Dada la atribución cultural en base al registro lítico y la serie cronológica (niveles IV y II), los resultados se presentan divididos en dos bloques: el nivel I definido como posible Solútreo-gravetiense; y de forma conjunta los resultados que proceden de los niveles II a IV, y que corresponderían al Gravetiense.

\subsection{ESPECTRO TAXONÓMICO Y ANATÓMICO}

El conjunto de fauna asciende a 2029 restos: 1317 (niveles IV-II) y 712 (nivel I). Se ha identificado taxonómica y anatómicamente el $17 \%$ de ellos, un porcentaje muy bajo para tratarse de un yacimiento del Paleolítico superior. Esto se debe a la elevada fragmentación y la mala conservación del conjunto.

En el espectro taxonómico se han identificado cinco especies en el rango de género o especie: Equus sp., Bos primigenius, Capra pyrenaica, Cervus elaphus y Oryctolagus cuniculus, y un resto en el rango de familia, Felidae (Fig. 11). Todos los taxones están representados por al menos un individuo, salvo los lepóridos cuyo NMI alcanza 7 (nivel I) y 6 (niveles II-IV).

La mayoría de las especies están presentes en los dos bloques, salvo en el caso del équido, el uro y el felino, cuyo registro es muy puntual. En términos de porcentaje de NISP sobre el total de restos determinados (Fig. 12: a), en los dos bloques predominan los lepóridos con porcentajes altos: 86\% (nivel I), y 84\% (niveles II-IV). Entre los ungulados destaca la cabra con valores que alcanzan hasta el $12,4 \%$ en el Gravetiense, puesto que la presencia del resto de taxones es muy reducida, por debajo del 3\%. Es relevante la presencia de un fragmento de calcáneo sin osificar de felino en el Gravetiense.

Todos los grupos anatómicos de las especies más numerosas (Capra y Leporidae) están representados en la muestra (Fig. 13) aunque en proporciones diferentes. En el caso de la cabra, están presentes los principales huesos largos y falanges, así como algunos elementos del esqueleto craneal, pero tan solo una vértebra torácica en el Gravetiense. No obstante, las cantidades son tan reducidas por bloque que es complicado realizar una valoración con relación al transporte completo o parcial de esta presa. Lo mismo le sucede, y todavía con mayor acuse, al ciervo y al resto de ungulados.

En cuanto al grupo de Leporidae (Fig. 12: b), el miembro posterior es el mejor representado con porcentajes que superan el $40 \%$ en ambos bloques, seguido del miembro anterior en el Solútreo-gravetiense con valores cercanos al $20 \%$, y de las extremidades $(28 \%)$ y el miembro anterior $(23,1 \%)$ en el Gravetiense. La presencia de elementos de la parte craneal es algo desigual, con un $15 \%$ (S-G) y un $8,8 \%(\mathrm{G})$. Por último, el

\begin{tabular}{|l|c|c|c|c|c|c|}
\cline { 2 - 7 } \multicolumn{1}{c|}{} & \multicolumn{2}{c|}{ IV } & \multicolumn{2}{c|}{ II } & \multicolumn{2}{c|}{ I } \\
\cline { 2 - 7 } \multicolumn{1}{c|}{ NISP } & $\mathbf{\% N I S P}$ & NISP & $\mathbf{\% N I S P}$ & NISP & \%NISP \\
\hline DETERMINADOS & $\mathbf{9 5}$ & 27,7 & $\mathbf{5 7}$ & 16,5 & $\mathbf{1 5 5}$ & 21,8 \\
\hline Artiodactyla & & & 2 & 0,6 & 5 & 0,7 \\
\hline Equus sp. & 1 & 0,3 & 1 & 0,3 & & \\
\hline Bos primigenius & & & & & 1 & 0,1 \\
\hline Capra pyrenaica & 4 & 1,2 & 13 & 3,8 & 14 & 2,0 \\
\hline Cervus elaphus & 3 & 0,9 & 1 & 0,3 & 5 & 0,7 \\
\hline Felidae & & & 1 & 0,3 & & \\
\hline Leporidae & 87 & 25,4 & 3 & 0,9 & 29 & 4,1 \\
\hline Oryctolagus cuniculus & & & 34 & 9,8 & 99 & 13,9 \\
\hline Aves & & & $\mathbf{2}$ & 0,6 & $\mathbf{2}$ & 0,3 \\
\hline INDETERMINADOS & $\mathbf{2 4 8}$ & 72,3 & $\mathbf{2 8 9}$ & 83,5 & $\mathbf{5 5 7}$ & 78,2 \\
\hline Esquirlas & 204 & 59,5 & 234 & 67,6 & 456 & 64,0 \\
\hline Talla muy pequeña & 22 & 6,4 & 18 & 5,2 & 46 & 6,5 \\
\hline Talla pequeña & & & & & 1 & 0,1 \\
\hline Talla media & 21 & 6,1 & 37 & 10,7 & 51 & 7,2 \\
\hline Talla grande & 1 & 0,3 & & & 3 & 0,4 \\
\hline & $\mathbf{3 4 3}$ & & $\mathbf{3 4 6}$ & & $\mathbf{7 1 2}$ & \\
\hline
\end{tabular}

Figura 11: Clasificación taxonómica de los restos de fauna de la Ratlla del Bubo por niveles 
a)

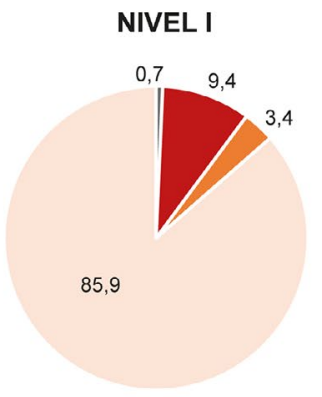

NIVELES II-IV

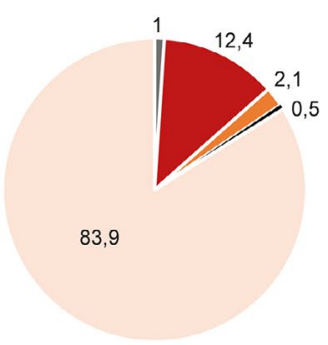

Nivel I

Niveles II-IV

c)

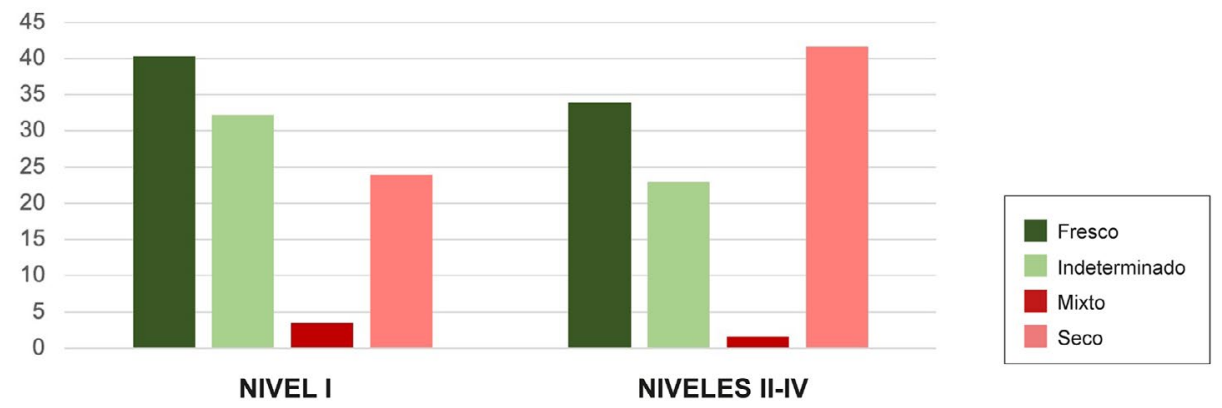

Figura 12: a) Distribución porcentual de los taxones identificados; b) Representación anatómica de los restos de Leporidae; c) Origen de las fracturas sobre huesos determinados

esqueleto axial está ínfimamente representado $(8,4 \%$ y $0,7 \%$ respectivamente).

En cuanto a los restos indeterminados, entre el 84,3$89 \%$, son esquirlas, restos menores de $2 \mathrm{~cm}$ que no han podido ser identificados. Entre los que sí han podido ser clasificados por talla y tipo de hueso, destacan por un lado los restos de talla media, que comprenden sobre todo fragmentos de hueso largo, y elementos axiales y esponjosos. Por otro lado, también cabe señalar la presencia de restos de talla muy pequeña que podrían vincularse con los lepóridos, la mayoría fragmentos de hueso largo.

\subsection{ANÁLISIS TAFONÓMICO}

Como ya se ha indicado, el conjunto óseo de la Ratlla del Bubo está muy alterado postdeposicionalmente. Se registran diversas alteraciones diagenéticas como vermiculaciones, manchas de manganeso, corrosión química, meteorización, concreción y erosión, siendo estas dos últimas las más numerosas en términos de porcentaje de restos afectados (Figs. 14 y 15: a).
La fragmentación en los tres niveles es muy alta: si se excluyen los restos con fracturas recientes, los huesos fragmentados alcanzan $91 \%$ (S-G) y $87,7 \%(\mathrm{G})$ sobre los restos identificables (NISP $=407$ ), tan solo 44 huesos están completos. Además, entre el 83-86\% del conjunto está por debajo de los $2 \mathrm{~cm}$ de longitud.

En cuanto al origen de las fracturas (excluyendo los huesos con fracturas recientes), se han registrado tanto frescas como secas en los dos bloques de la secuencia, además de un elevado número de indeterminadas en el nivel I (Fig. 12: c). Los porcentajes altos de fracturas secas (entre $24-41,7 \%$ ) hacen referencia a la fuerte alteración postdeposicional que ha sufrido el yacimiento. No obstante, también se registran fracturas frescas en elementos de cabra, talla media y lepóridos, que se pueden vincular con las actividades antrópicas llevadas a cabo en él. En el caso de la talla media, se trata de fragmentos de diáfisis de huesos largos (Fig. 15: b) y metatarsos con circunferencia incompleta y fragmentos de falanges que conservan parte articular, principalmente la distal (Fig. 15: c). En cuanto a los lepóridos, destacan los fragmentos de diáfisis incompleta junto 


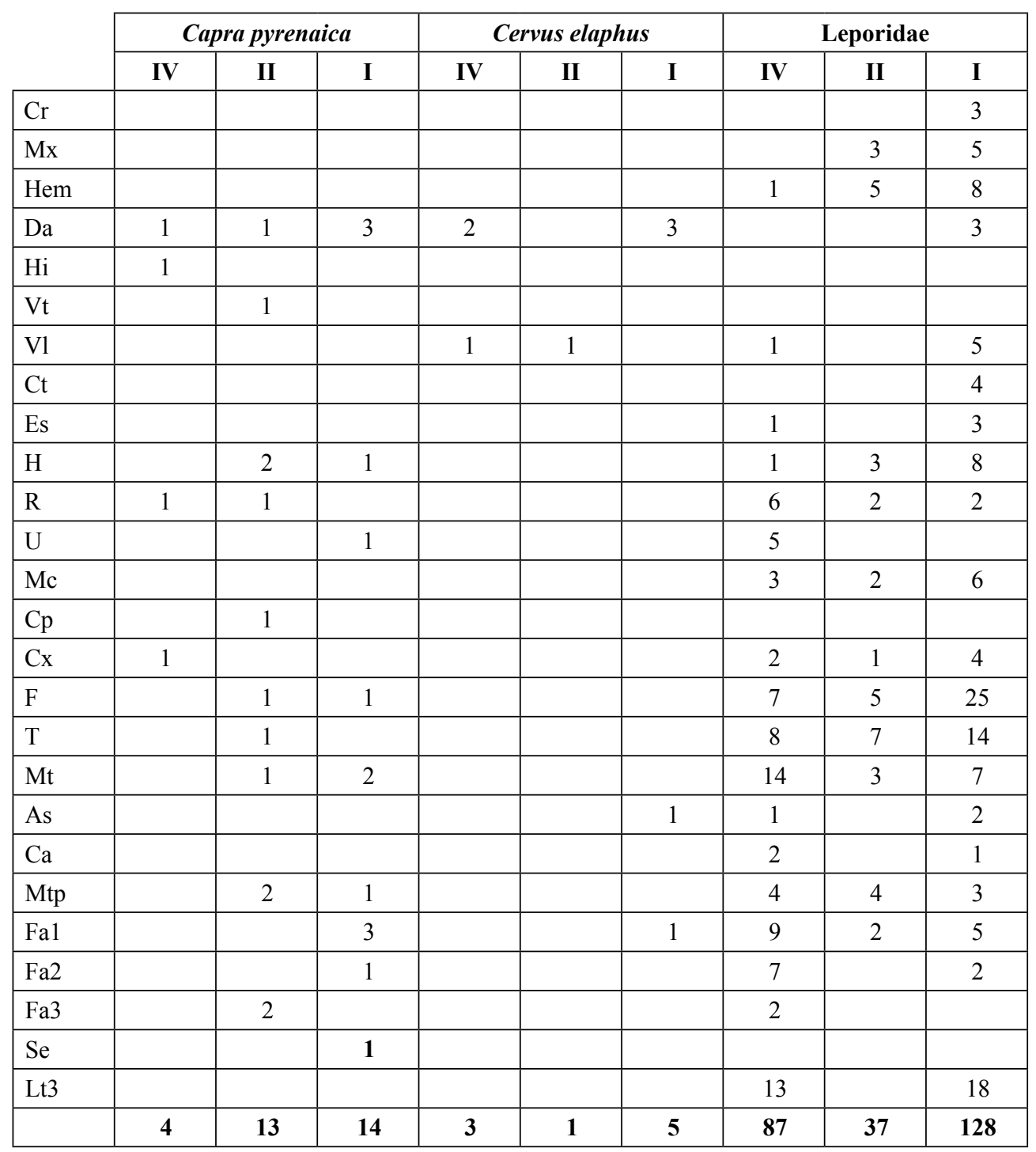

Figura 13: Elementos anatómicos (NISP) de las tres principales especies por nivel. Abreviaturas: cráneo (Cr), maxilar (Mx), mandíbula $(\mathrm{Hem})$, dientes $(\mathrm{Da})$, hioides $(\mathrm{Hi})$, vértebra torácica $(\mathrm{Vt})$, vértebra lumbar $(\mathrm{Vl})$, costilla $(\mathrm{Ct})$, escápula $(\mathrm{Es})$, húmero $(\mathrm{H})$, radio $(\mathrm{R})$, ulna $(\mathrm{U})$, metacarpo $(\mathrm{Mc})$, carpo $(\mathrm{Cp})$, coxal $(\mathrm{Cx})$, fémur $(\mathrm{F})$, tibia $(\mathrm{T})$, metatarso $(\mathrm{Mt})$, astrágalo $(\mathrm{As})$, calcáneo $(\mathrm{Ca})$, metapodio indeterminado (Mtp), falange (Fa), sesamoideo (Se), Lt3 (hueso largo indeterminado de Leporidae)

con cilindros (Fig. 15: g), y algunos fragmentos que también conservan la articulación distal en el caso del húmero, la tibia y el radio, las cuales son más densas que sus proximales.

En cuanto a las modificaciones, tan solo se han identificado unas pocas modificaciones de origen antrópico: dos muescas sobre huesos largos de lepóridos producidas por mordedura y varios casos de marcas de corte (Figs. 14 y 15). En el caso de las marcas líticas, todas ellas son incisiones localizadas sobre diáfisis de huesos largos: húmero de cabra, fémur de conejo, dos huesos largos de talla media y un fragmento de esquirla. Como caso relevante, también se han identificado incisiones múltiples y cortas sobre un hioides de cabra, que, además, está quemado.

Las termoalteraciones afectan a buena parte de la muestra (Fig. 14): 16,2\% (nivel I) y 34,9\% (niveles II-IV) del total, con mayor presencia entre las esquirlas que concentran el $83,8 \%$ de los restos quemados. En el Solútreo-gravetiense destacan los huesos quemados con coloración marrón/negra (48,7\%); en cambio, en el Gravetiense, los porcentajes de intensidad están más igualados, aun así sobresalen los restos carbonizados (37,8\%). Estas alteraciones por fuego afectan a toda la superficie por igual en la mayor parte de los casos, aunque se han identificado seis restos en el Gravetiense que presentan termoalteraciones parciales o puntuales (Fig. 15: d).

\subsection{VALORACIÓN DEL CONJUNTO ÓSEO}

El estudio nos sitúa ante un conjunto óseo reducido, bastante mal conservado y muy fragmentado, lo que dificulta llevar a cabo una valoración adecuada de las actividades de subsistencia, aunque se pueden extraer ciertas características. 


\begin{tabular}{|l|c|c|c|c|}
\cline { 2 - 5 } \multicolumn{1}{c|}{} & IV & II & I & TOTAL \\
\hline Incisión & $\mathbf{1}$ & $\mathbf{2}$ & $\mathbf{3}$ & $\mathbf{3}$ \\
\hline Capra pyrenaica & 1 & 1 & & 2 \\
\hline Leporidae & & & 1 & 0 \\
\hline Talla media & & 1 & 1 & 1 \\
\hline Indeterminado & & & 1 & 0 \\
\hline Muesca & & $\mathbf{1}$ & $\mathbf{1}$ & $\mathbf{1}$ \\
\hline Leporidae & & 1 & 1 & 1 \\
\hline Termoalteraciones & $\mathbf{1 1 1}$ & $\mathbf{8 3}$ & $\mathbf{1 1 5}$ & $\mathbf{1 9 4}$ \\
\hline Intensidad 1 & 27 & 22 & 56 & 49 \\
\hline Intensidad 2 & 50 & 32 & 36 & 82 \\
\hline Intensidad 3 & 34 & 29 & 23 & 63 \\
\hline Diagénesis & $\mathbf{3 6 2}$ & $\mathbf{1 9 3}$ & $\mathbf{2 9 0}$ & $\mathbf{5 5 5}$ \\
\hline Raíces & & 9 & 3 & 9 \\
\hline Manganeso & 10 & 27 & 37 & 37 \\
\hline Corrosión & 9 & & 2 & 9 \\
\hline Concreción & 123 & 50 & 117 & 173 \\
\hline Erosión & 198 & 89 & 113 & 287 \\
\hline Meteorización & 22 & 18 & 18 & 40 \\
\hline
\end{tabular}

Figura 14: Modificaciones antrópicas y alteraciones identificas en la fauna por tipo y taxón

El espectro taxonómico coincide con el ya visto en otros yacimientos de la zona mediterránea de la península ibérica, en la cual la presencia de especies de ungulados de talla media y grande se combina con lepóridos y carnívoros de talla media-pequeña (p. ej. Villaverde et al., 2019, 2021). En este caso, destacan en número de restos la cabra, como presa tipo de talla media, y los lepóridos, con proporciones similares en ambas fases cronológicas. Tan solo hay un resto de carnívoro en el Gravetiense, aunque no se puede determinar el origen de su aporte.

En base a la representación anatómica, a las fracturas y a las modificaciones, se deduce que las acumulaciones tienen un origen antrópico tanto en el paquete solútreo-gravetiense como en el gravetiense. Los grupos humanos parecen haber aprovechado al menos la carne y la médula de estas presas, como muestran las incisiones a lo largo de las diáfisis de huesos largos, y la fractura sistemática de los mismos. Este patrón puede ser aplicado tanto a la cabra como a los lepóridos. Además, la presencia de marcas de corte sobre el hioides de cabra podría vincularse con el propio aprovechamiento alimenticio, en este caso, de la lengua.

Las termoalteraciones están muy generalizadas en el conjunto óseo, pero no queda claro si el uso del fuego está siempre vinculado al procesado de las carcasas para su consumo (tratamiento culinario), o responde más bien a cuestiones postdeposicionales, por contacto con hogares, o tareas de limpieza. No obstante, un carpo y una falange tercera de cabra con quemados puntuales podrían relacionarse con un asado de ciertas partes anatómicas. En el proceso de excavación se documentó un hogar en el nivel II, uno parcialmente afectado por las excavaciones clandestinas en el III-IV y otro en el IV, y hay que señalar que las evidencias del uso del fuego están presentes en todos los niveles, en forma de carbones, manchones de cenizas y piedras rubefactas (Fig. 2: c).

El bajo número de materiales y la integridad de los hogares documentados indican que la frecuentación humana debió de ser baja y que las alteraciones estratigráficas a las que apuntan las dataciones obtenidas deben tener su origen en razones de carácter climático y bioturbaciones, estas últimas importantes en el contexto regional. Dadas las dimensiones del abrigo y la baja densidad de restos, con dominio de pocas especies animales, resulta muy probable que se trate de ocupaciones temporales centradas en la explotación de la cabra y el conejo.

\section{DISCUSIÓN Y CONCLUSIONES}

A comienzos de la década de los noventa del siglo XX, los niveles I y II del Abrigo de la Ratlla del Bubo se relacionaron con el tecnocomplejo Solútreogravetiense. En esta asignación jugaron un papel fundamental la existencia de algún material lítico de tipología definida (nivel I) y una datación obtenida para un hogar del nivel II. Sin embargo, el presente estudio ha permitido revisar la atribución del nivel II y limitar la adscripción solútreo-gravetiense al nivel I. El material recuperado en las campañas de 1986 a 1991 es reducido para este nivel, pero la asociación de puntas escotadas y retoque plano resulta significativa. Y en ese mismo orden de cosas, es importante recordar que entre los materiales recuperados por clandestinos se documentan otras dos puntas escotadas y dos puntas de pedúnculo y aletas, así como una punta de retoque bifacial no cubriente. La escasa presencia de retoque plano no resulta extraña, pues es una característica general del final del Solutrense regional y la asociación de puntas de pedúnculo y aletas y puntas escotadas se observa en la mayor parte de los yacimientos en los que se ha documentado esta fase (Rodrigo, 1988). En los materiales de nivel I, las proporciones de puntas escotadas $\mathrm{y}$ retoques planos presentan similitud con los yacimientos de Barranc Blanc (capas BB1 y BB2), donde solo se recuperaron tres puntas escotadas y el grupo solutrense presenta valores reducidos entre $1,1 \%$ y $1,56 \%$ (Villaverde y Peña, 1981), o Cova de Les Calaveres (I y II) en la que fue recuperada una punta escotada (Aparicio et al., 1982), mientras contrastan con los índices de yacimientos como Parpalló (Fullola, 1979), Beneito (Iturbe et al., 1993), Cendres (Martínez-Alfaro et al., 2019) o Ambrosio (Ripoll, 1988) en los que las puntas escotadas son numerosas. En el caso de Parpalló las puntas escotadas experimentan una clara variación a lo largo del Solutrense evolucionado: no son especialmente numerosas en el Solutrense superior, abundan 


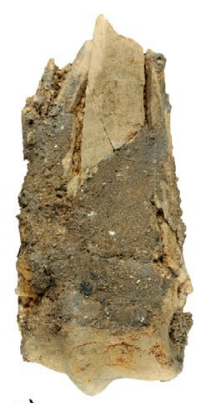

a)

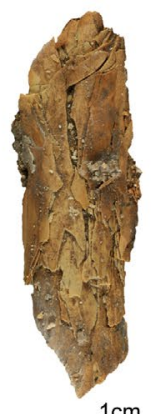

$\underline{1 \mathrm{~cm}}$

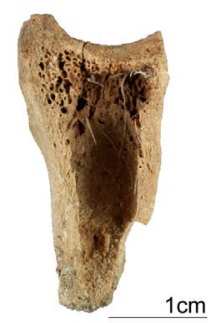

c)
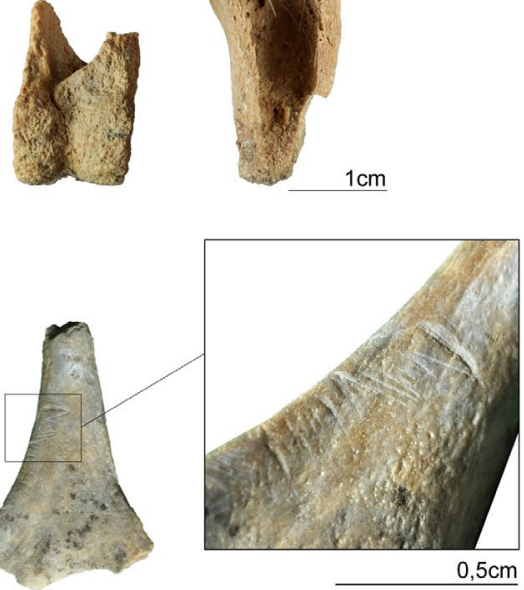

e)

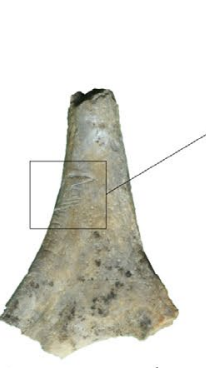
$1 \mathrm{~cm}$

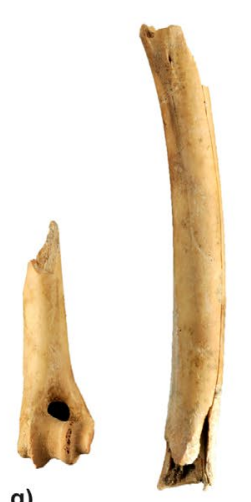

g)

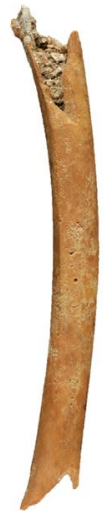

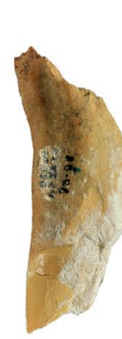

b)

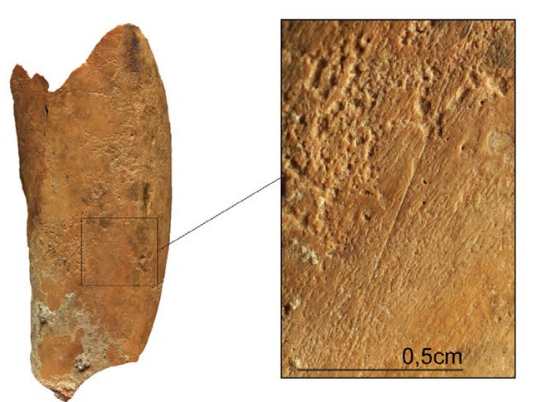

$1 \mathrm{~cm}$

d)

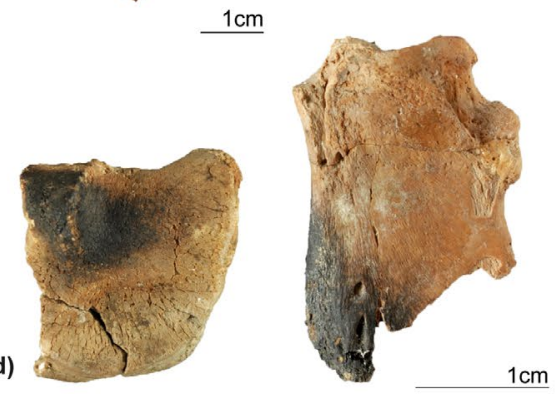

Figura 15: A. Restos de fauna con alteraciones diagenéticas. B. Huesos largos de cabra con fractura fresca y uno con una incisión. C. Falanges de cabra con fractura fresca. D. Carpo y falange tercera de cabra con termoalteración parcial. E. Hioides de cabra con incisiones y termoalteración. F. Marcas líticas. G. Huesos largos de Leporidae con fracturas en fresco y modificaciones (una muesca y incisiones líticas)

en el tramo entre 5 y $4,25 \mathrm{~m}$ de potencia, coincidiendo con el Solútreo-gravetiense, y su frecuencia vuelve a descender al final de este, al igual que el retoque plano y las puntas de pedúnculo y aletas.

Las ocupaciones de los niveles IV al II, a pesar de las incongruencias que presentan algunas de las dataciones obtenidas, se puede caracterizar gracias al material lítico diagnóstico. Así, el conjunto de piezas de dorso es claramente gravetiense, integrado fundamentalmente por laminitas de dorso, tanto apuntadas como no apuntadas, con tres microlaminitas de dorso. Además, los proyectiles de mayor tamaño también están bien documentados, tanto puntas de La Gravette y de Vachons, como microgravettes, así como un ejemplar de punta 
tipo Cendres, una variante de punta sin dorso documentada en varios conjuntos gravetienses regionales (Villaverde, Martínez-Alfaro y Bel, 2021; Villaverde y Roman, 2004). A la vista del material lítico recuperado es posible considerar que las alteraciones observadas en las dataciones obtenidas solo afectan a algunos carbones y no a la integridad de la secuencia gravetiense. De hecho, en términos generales, sería incluso posible distinguir dos fases atendiendo a la información disponible: 1) una que correspondería a los niveles IV y III, que son los que menor número de restos han aportado y presentan menor diversidad tipológica tanto en útiles domésticos como piezas de dorso; y 2) otra que coincidiría con el nivel II, que es más rico industrialmente, lo que podría implicar una mayor reiteración de las ocupaciones, y se caracteriza por una variedad tipológica en la que resalta el abundante número de piezas de dorso. Se observaría, por tanto, una diferencia secuencial en la que las primeras ocupaciones gravetienses se caracterizan por una amplia potencia estratigráfica con un número de restos reducido, mientras que las ocupaciones gravetienses más recientes, en términos estratigráficos, aportarían un registro más rico y con una diversidad tipológica destacable en el grupo de dorsos y en el componente microlaminar. Esta tendencia diacrónica encuentra paralelos en yacimientos mediterráneos como la Cova de les Malladetes (Villaverde et al., 2021), la Cova de les Cendres (Villaverde et al., 2019) o el Abrigo de La Boja (Zilhão et al., 2017).

Tras el análisis crítico de las dataciones obtenidas, se puede considerar que las ocupaciones gravetienses de la Ratlla del Bubo se situarían, al menos, entre el 29.050-28.300 cal BP del nivel IV y el 27.900-25.280 cal BP del nivel II. Una reciente revisión de la cronología del Gravetiense en el ámbito mediterráneo ha situado este tecnocomplejo en el territorio valenciano entre el 31.700-30.900 cal BP y el 25.500-25.100 cal BP (Villaverde, Martínez-Alfaro y Bel, 2021). En Cendres el nivel XVIB se sitúa cronológicamente entre 31.000-29.300 cal BP, en Malladetes el nivel XI entre 31.000-29.800 cal BP y OH13/OH14 en La Boja entre 31.500-30.900 cal BP, siendo este último el que mayor distancia cronológica presenta. Todos estos niveles constituyen los inicios del Gravetiense en los respectivos yacimientos. El Gravetiense medio es el momento en que el registro material es más numeroso en estos tres enclaves, con una cronología para el nivel XVIA de Cendres de 29.200-27.400 cal BP, niveles $\mathrm{X}$ al VII de Malladetes entre 28.600-27.200 cal BP y OH12 de La Boja entre 27.700-27.400 cal BP. De estos tres yacimientos, el final del Gravetiense solo ha sido documentado en el nivel XV de Cendres datado entre 26.500-25.300 cal BP y se caracteriza por un empobrecimiento industrial respecto al Gravetiense pleno del nivel XVIA. En definitiva, la franja cronológica a la que remiten los niveles IV al II incluye gran parte de la cronología del Gravetiense regional, el final del tecnocomplejo en la Ratlla del Bubo sí coincidiría con el de su final en el contexto regional y su inicio sería posterior al observado en otros yacimientos de ese mismo ámbito. No obstante, debemos tener en cuenta que la secuencia excavada entre 1986 y 1991 no alcanzó los niveles auriñacienses excavados en el yacimiento en 1984 (Iturbe y Cortell, 1992), por lo que puede haber estratos gravetienses todavía sin excavar.

Los resultados aportados por el estudio de los restos vegetales y faunísticos resultan plenamente coherentes con la propuesta secuencial realizada en este trabajo y contribuyen a una mejor comprensión de la ocupación humana de la zona y la utilización de los recursos durante el Gravetiense y el Solútreo-gravetiense. Especialmente si tenemos en cuenta la posición estratégica que ocupa el yacimiento en relación con la ocupación también documentada en la región de Murcia para esas mismas cronologías.

El conjunto de la información apunta a un patrón de ocupación caracterizado por estancias cortas y probablemente estacionales, con densidades de materiales líticos bajas que en su mayor parte responden a un aprovisionamiento inmediato de materias primas para la confección del utillaje. La posición en la Serra de Crevillent explica, por otra parte, la importancia de la cabra en la alimentación, complementada, como es habitual en los contextos superopaleolíticos, por el consumo de lepóridos.

En conclusión, con los datos que en este trabajo se presentan, es posible considerar que el relleno sedimentario incluyó, al menos, niveles del Auriñaciense evolucionado, el Gravetiense y el Solutrense evolucionado o Solútreo-gravetiense. La amplitud de la secuencia de la Ratlla del Bubo supone un importante avance en el conocimiento del poblamiento del área sur de Alicante durante el Paleolítico superior inicial. Aunque se tenía constancia, por la tipología de algunos materiales recuperados en excavaciones clandestinas (Menargues y Navarro, 2001) y por los resultados de las excavaciones de Iturbe y Lajarín (Iturbe y Cortell, 1992), de la existencia de ocupaciones auriñacienses y gravetienses, los resultados ahora presentados confirman la importancia del Paleolítico superior inicial en la secuencia del yacimiento.

Estos resultados incitan a analizar con nuevos planteamientos el contexto territorial más inmediato a la Ratlla del Bubo, en el que se han identificado algunos materiales relacionables con los tecnocomplejos del Paleolítico superior. Así, en el reciente estudio de los materiales de superficie del Abric del Corral de les Paleres, también en la Serra de Crevillent, tras considerar la importancia de los niveles solútreo-gravetienses de la Ratlla del Bubo, y en ausencia de material diagnóstico, los autores optan por descartar la posibilidad de que parte de los materiales recogidos puedan corresponder al Paleolítico superior inicial, concretamente al Auriñaciense y Gravetienses y relacionan los elementos de dorso con un Magdaleniense final (Molina et al., 2020). No obstante, la dilatada secuencia gravetiense en la Ratlla del Bubo abre la posibilidad de que, al 
menos, una parte de las ocupaciones del Corral de les Paleres pudieran desarrollarse durante el Gravetiense. Además, si tenemos en cuenta que también se menciona la recuperación de algunos raspadores carenados y en hocico - presentes en los niveles del Auriñaciense evolucionado de la Ratlla del Bubo- y material solutrense, con cautela de un conjunto superficial, no sería descabellado plantear que las ocupaciones de este yacimiento remitan a una secuencia similar a la de la Ratlla del Bubo.

Otras secuencias con posibles ocupaciones gravetienses son las de la Cueva del Sol en Hondón de las Nieves (Miralles, 1982) o de la Cova del Xorret en Crevillent (Serna, 1991), aunque para este último también se ha planteado una cronología Magdaleniense (Casabó, 2004) a partir de la tipología de algunos materiales. Algo que ya se sugirió en la publicación del conjunto y que no entra en contradicción con que el lugar tuviera distintas fases de ocupación durante el Paleolítico superior. Respecto a las ocupaciones solutrenses se han recuperado materiales en el Abrigo de La Horna (Aspe) (Belmonte, Molina y Satorre, 2018) y con dudas en la Cueva del Sol en la que se recuperó una punta de aletas y pedúnculo y otra escotada (García Gandía, 2008).

En definitiva, resultados obtenidos en la Ratlla del Bubo permiten mejorar el conocimiento del Paleolítico superior inicial y medio al sur de Alicante y correlacionan con claridad con los datos disponibles para las comarcas valencianas meridionales (Villaverde et al., 2019; 2021) y el ámbito de Murcia (Zilhão et al., 2017). Nuevos trabajos en el yacimiento permitirán profundizar en los datos tratados en este trabajo y ampliar la información disponible tanto para el Gravetiense como para el Auriñaciense, cuyo material de 1984 se encuentra en revisión, y alcanzar, lo que resulta más necesario, la base de la secuencia arqueológica.

\section{REFERENCIAS}

Aparicio, J., Pérez-Ripoll, M., Vives, E., Fumanal, M. P. y Dupré, M. (1982). La Cova de les Calaveres (Benidoleig, Alicante). Serie de Trabajos Varios del SIP, 75. Valencia: Servicio de Investigación Prehistórica, Diputación Provincial de Valencia. Recuperado de: http://mupreva.org/pub/106/es

Badal, E. (1991). Aportaciones de la antracología al estudio del paisaje vegetal y su evolución en el Cuaternario reciente: en la costa mediterránea del País Valenciano y Andalucía (18.000-3.000 B.P.). (Tesis doctoral). Universitat de Valencia Valencia. Recuperado de: http://hdl.handle.net/10550/38492

Badal, E. (1992). L'anthracologie préhistorique: à propos de certains problèmes méthodologiques. Bulletin de la Société Botanique de France. Actualités Botaniques, 139(2-4), 167189. DOI: https://doi.org/10.1080/01811789.1992.10827098

Badal, E. (1995). La vegetación carbonizada: resultados antracológicos del País Valenciano. En AEQUA (Ed.). El cuaternario del País Valenciano (pp. 217-226). Valencia: Universitat de València.

Badal, E. (2012). Ratlla del Bubo, Alicante. En J.S. Carrión (Ed.). Paleoflora y paleovegetación de la península Ibérica e islas Baleares: Plioceno-Cuaternario (pp. 634-635). Murcia: Ministerio de Economía y Competitividad - Universidad de Murcia - Fundación Séneca.

Badal, E. y Carrión, Y. (2001). Del Glaciar al Interglaciar: los paisajes vegetales a partir de los restos carbonizados hallados en las cuevas de Alicante. En V. Villaverde (Ed.). De Neandertales a Cromañones: el inicio del poblamiento humano en las tierras valencianas. Valencia: Servei de Publicacions de l'Universitat de València.

Badal, E., Martínez-Varea, C. M., Cantó, A., Angelucci, D. E., Villaverde, V., Zapata, J. y Zilhão, J. (2019). Firewood in the fireplace : Fuel use in the Solutrean of La Boja rockshelter (Murcia, Spain). En I. Schmidt, J. Cascalheira, N. Bicho y G.-C. Weniger (Eds.). Human Adaptations to the Last Glacial Maximum: the Solutrean and its Neighbors (pp. 337-354). Cambridge: Cambridge Scholars Publishing.

Belmonte, D., Molina, F. J. y Satorre, A. (2018b). Nuevos yacimientos del Paleolítico superior y del Eneolítico en la sierra de la Horna (Vinalopó Medio, Aspe, Alicante). Lucentum, XXXVII, 9-32. DOI: https://doi.org/10.14198/ LVCENTVM2018.37.01

Binford, L. (1981). Bones: Ancient Men and Modern Myths. Academic Press. New York: Academic Press. DOI: https:// doi.org/10.1016/C2013-0-07180-0

Bromage, T. G. y Boyde, A. (1984). Microscopic criteria for the determination of directionality of cutmarks on bone. American Journal of Physical Anthropology, 65(4), 359-366. DOI: https://doi.org/10.1002/ajpa.1330650404

Bronk Ramsey, C. (2009a). Bayesian Analysis of Radiocarbon Dates. Radiocarbon, 51(1), 337-360. DOI: https://doi. org/10.1017/S0033822200033865

Bronk Ramsey, C. (2009b). Dealing with Outliers and Offsets in Radiocarbon Dating. Radiocarbon, 51(3), 1023-1045. DOI: https://doi.org/10.1017/S0033822200034093

Bronk Ramsey, C. (2017). Methods for Summarizing Radiocarbon Datasets. Radiocarbon, 59(6), 1809-1833. DOI: https://doi.org/10.1017/RDC.2017.108

Carrión, Y., Ntinou, M. y Badal, E. (2010). Olea europaea L. in the North Mediterranean Basin during the Pleniglacial and the Early-Middle Holocene. Quaternary Science Reviews, 29(7-8), 952-968. DOI: https://doi.org/10.1016/j. quascirev.2009.12.015

Casabó, J. (2004). Paleolitico Superior Final y Epipaleolitico en la Comunidad Valenciana. Serie Mayor, 3. Alicante: MARQ Museo Arqueológico Provincial de Alicante, Diputación Provincial de Alicante.

Chabal, L. (1988). Pourquoi et comment prélever les charbons de bois pour la période antique: les méthodes utilisées sur le site de Lattes (Hérault). Lattara, 1, 187-222.

Fullola, J. M. (1979). Las industrias líticas del Paleolítico Superior Ibérico. Serie de Trabajos Varios del SIP, 60. 
Valencia: Servicio de Investigación Prehistórica, Diputación Provincial de Valencia. Recuperado de: http://mupreva.org/ pub/91/es

García Gandía, J. R. (2008). Arqueología en Aspe. Poblamiento y territorio. Aspe: Ayuntamiento de Aspe.

Inizan, M. L., Tixier, J., Roche, H. y Reduron-Ballinger, M. (1995). Technologie de la pierre taillée. Meudon: Centre de Recherches et d'Études préhistoriques, CNRS.

Iturbe, G. y Cortell, E. (1992). El Auriñaciense evolucionado en el País Valenciano: En M. P. Utrilla y J. Maluquer de Motes (Eds.). Aragón-litoral Mediterráneo. Intercambios culturales durante la Prehistoria (pp. 129-138). Zaragoza: Institución Fernando el Católico.

Iturbe, G., Fumanal, M. P., Carrión, J. S., Cortell, E., Martínez, R., Guillem, P. M.,... y Vandermeersch, B. (1993). Cova Beneito (Muro, Alicante): una perspectiva interdisciplinar. Recerques del Museu d'Alcoi, 2, 23-88.

Lyman, R. L. (1994). Vertebrate Taphonomy. Cambridge Manuals in Archaeology. Cambridge: Cambridge University Press. DOI: https://doi.org/10.1017/CBO9781139878302

Lyman, R. L. (2008). Quantitative Paleozoology. Cambridge Manuals in Archaeology. Cambridge: Cambridge University Press. DOI: https://doi.org/10.1017/CBO9780511813863

Mangado, X. (2005). La caracterización y el aprovisionamiento de los recursos abióticos en la Prehistoria de Cataluña. Las materias primas siliceas del Paleolítico Superior Final y el Epipaleolitico. BAR International Series, 1420. Oxford: British Archaeological Reports Oxford.

Martínez-Alfaro, Á., Bel, M. Á., Roman, D. y Villaverde, V. (2019). Techno-typological and Lithic taphonomic study in the Solutrean of Cova de les Cendres (Alicante, Spain). En I. Schmidt, J. Cascalheira, N. Bicho y G.-C. Weniger (Eds.). Human Adaptations to the Last Glacial Maximum: the Solutrean and its Neighbors (pp. 236-254). Cambridge: Cambridge Scholars Publishing.

Martínez-Alfaro, Á., Bel, M. Á. y Villaverde, V. (2021). New advances on the Aurignacian in the central Iberian Mediterranean basin. L'Anthropologie, 125(2), 102852. DOI: https:// doi.org/10.1016/j.anthro.2021.102852

Martínez-Varea, C. M. (2020). Gathering in the dunes. Seeds and fruits from the Gravettian levels of Cova de les Cendres (Teulada-Moraira, Alicante, Spain). Journal of Archaeological Science: Reports, 33, 102540. DOI: https://doi. org/10.1016/j.jasrep.2020.102540

Masson, A. (1979). Recherches sur la provenance des silex préhistoriques. Méthode d'étude. Études Préhistoriques, 15, $29-40$.

Menargues, J. (2000). Localización y caracterización de las fuentes de materias primas siliceas en la cuenca del Vinalopó. Aplicación al estudio material del Paleolítico superior del yacimiento de la Ratlla del Bubo (Crevillent, Alacant) (Tesis de licenciatura, inédita). Valencia: Universitat de València.

Menargues, J. (2005). La explotación de las rocas locales en los yacimientos paleolíticos de la Ratlla del Bubo (Crevillent, Alicante) y la Cova de les Cendres (Teulada, Alicante). En
M. Santonja, A. Pérez-González y M. J. Machado (Eds.). Geoarqueología y Patrimonio en la Península Ibérica y el entorno mediterráneo (pp. 413-424). Soria: ADEMA.

Menargues, J. y Navarro, C. (2001). Los materiales paleolíticos de la Ratlla del Bubo (Crevillent, Alacant) en el Museo Arqueológico Municipal de Novelda. Recerques del Museu d'Alcoi, 10, 17-24.

Miralles, J. L. (1982). El Gravetiense en el País Valenciano. (Tesina inédita). Valencia: Universitat de València.

Molina, F. J. (2016). El sílex del Prebético y cuencas neógenas en Alicante y sur de Valencia: su caracterización y estudio aplicado al Paleolítico medio. (Tesis doctoral). Alicante: Universitat d'Alacant. Recuperado de: http://hdl. handle.net/10045/56446

Molina, F. J., Casabó, J. A., Belmonte Mas, D. y Satorre, A. (2020). El Paleolítico superior del abrigo del Corral de les Paleres (Crevillent): análisis tecnotipológico y litológico de la industria lítica. Lucentum, XXXIX, 9-29. DOI: https://doi. org/10.14198/LVCENTVM2020.39.01

Pelegrin, J. (1995). Technologie lithique : le châtelperronien de Roc-de-Combe, Lot, et de La Côte (Dordogne). Cahiers du Quaternaire, 20. Paris: CNRS Éditions.

Pelegrin, J. (2000). Les techniques de débitage laminaire au Tardiglaciaire : critères de diagnose et quelques réflexions. En B. Valentin, P. Bodu y M. Christensen (Eds.). Europe centrale et septentrionale au Tardiglaciare (pp. 73-85). Paris: Mémoires du Musée de Préhistoire d’Île-de-France.

Peña, P. de la. (2011). Sobre la identificación macroscópica de las piezas astilladas: propuesta experimental. Trabajos de Prehistoria, 68(1), 79-98. DOI: https://doi.org/10.3989/ tp.2011.11060

Pérez-Ripoll, M. (1992). Marcas de carnicería, fracturas intencionadas y mordeduras de carnivoros en huesos prehistóricos del mediterráneo español. Alicante: Instituto de Cultura «Juan-Gil Albert».

Potts, R. y Shipman, P. (1981). Cutmarks made by stone tools on bones from Olduvai Gorge, Tanzania. Nature, 291(5816), 577-580. DOI: https://doi.org/10.1038/291577a0

Real, C. (2017). Estudio arquezoológico y tafonómico del Magdaleniense de la Cova de les Cendres (Teulada-Moraira, Alicante). (Tesis doctoral). Valencia: Universitat de València. Recuperado de: http://hdl.handle.net/10550/58478

Reimer, P. J., Bard, E., Bayliss, A., Beck, J. W., Blackwell, P. G., Ramsey, C. B.,... y Friedrich, M. (2013). IntCal13 and Marine13 Radiocarbon Age Calibration Curves 0-50,000 Years cal BP. Radiocarbon, 55(4), 1869-1887. DOI: https:// doi.org/10.2458/azu js rc.55.16947

Ripoll, S. (1988). La cueva de Ambrosio (Almería, Spain) y su posición cronoestratigráfica en el Mediterráneo Occidental. BAR international series, 462. Oxford: British Archaeological Reports Oxford.

Rodrigo, M. J. (1988). El solutreo-gravetiense de la Cova del Parpalló (Gandía): algunas consideraciones sobre el solutreo-gravetiense en la secuencia del Paleolítico Superior del área mediterránea peninsular. Saguntum-PLAV , 21, 9-46. 
Recuperado de: https://ojs.uv.es/index.php/saguntum/article/ view/3715/3294

Serna, J. L. (1991). La industria lítica de la Cova del Xorret (Crevillent, Alicante). Saguntum-PLAV, 24, 9-21. Recuperado de: https://ojs.uv.es/index.php/saguntum/article/ view/3661

Shipman, P. y Rose, J. (1983). Early hominid hunting, butchering, and carcass-processing behaviors: Approaches to the fossil record. Journal of Anthropological Archaeology, 2(1), 57-98. DOI: https://doi.org/10.1016/0278-4165(83)90008-9

Soler, B. (2003). Estudios de las estructuras de combustión prehistóricas, una propuesta experimental: Cova Negra (Xàtiva, Valencia), Ratlla del Bubo (Crevillent, Alicante) y Marolles-sur-Seine (Bassin Parisien, Francia). Trabajos Varios del SIP, 102. Valencia: Servicio de Investigación Prehistórica, Diputación Provincial de Valencia. Recuperado de: http://mupreva.org/pub/133/es

Soler, B., Badal, E., Villaverde, V. y Aura Torsosa, J. E. (1990). Nota sobre un hogar Solútreo-gravetiense del Abric de la Ratlla del Bubo (Crevillent, Alicante). Archivo de Prehistoria Levantina, XX, 79-94.

Sonneville-Bordes, D. y Perrot, J. (1954). Lexique typologique du Paléolithique supérieur. Bulletin de la Société préhistorique française, 51(7), 327-335. DOI: https://doi. org/10.3406/bspf.1954.3106

Sonneville-Bordes, D. y Perrot, J. (1955). Lexique typologique du Paléolithique supérieur, Outillage lithique, III - Outils composites - Perçoirs. Bulletin de la Société préhistorique française, 52(1), 76-79. DOI: https://doi.org/10.3406/ bspf.1955.3156

Sonneville-Bordes, D. y Perrot, J. (1956a). Lexique typologique du Paléolithique supérieur. Bulletin de la Société préhistorique française, 53(9), 547-559. DOI: https://doi. org/10.3406/bspf.1956.3374

Sonneville-Bordes, D. y Perrot, J. (1956b). Lexique typologique du Paléolithique supérieur. Bulletin de la Société préhistorique française, 53(7), 408-412. DOI: https://doi. org/10.3406/bspf.1956.3357

Soulier, M.-C. (2016). Cutmark data and their implications for the planning depth of late Pleistocene societies. Journal of Human Evolution, 97, 37-57. DOI: https://doi.org/10.1016/j. jhevol.2016.05.006

Stiner, M. C., Kuhn, S. L., Weiner, S. y Bar-Yosef, O. (1995). Differential Burning, Recrystallization, and Fragmentation of Archaeological Bone. Journal of Archaeological Science, 22(2), 223-237. DOI: https://doi.org/10.1006/jasc.1995.0024

Théry-Parisot, I., Brugal, J.-P., Costamagno, S. y Guilbert, R. (2004). Conséquences taphonomiques de l'utilisation des ossements comme combustible. Approche expérimentale. Les Nouvelles de l'archéologie, 95, 19-22.

Tixier, J., Inizan, M. L. y Roche, H. (1980). Préhistoire de la pierre taillée. Terminologie et technologie. Valbonne: Centre de Recherches et d'Etudes préhistoriques, CNRS.
Vadillo, M., Ricci, G., Bencomo, M., Aura Tortosa, J. E. y Martini, F. (e. p.). A Review of Splintered Pieces from Two Lithic Assemblages in Mediterranean Europe: Grotta Della Serratura (Marina di Camerota, Italy) and Cueva de Nerja (Málaga, Spain). Lithic Technology. DOI: https://doi.org/10 1080/01977261.2021.1924477

Vettese, D., Blasco, B., Cáceres, I., Gaudzinski Windheuser, G., Moncell, M-H., Thun Hohenstein, U. y Daujeard, C. (2020). Towards an understanding of hominin marrow extraction strategies: a proposal for a percussion mark terminology. Archaeological and Anthropological Sciences, 12(48). DOI: https://doi.org/10.1007/s12520-019-00972-8

Villa, P. y Mahieu, E. (1991). Breakage patterns of human long bones. Journal of Human Evolution, 21(1), 27-48. DOI: https://doi.org/10.1016/0047-2484(91)90034-S

Villaverde, V., Martínez-Alfaro, Á. y Bel, M. Á. (2021). El Gravetiense de la región central mediterránea ibérica. Características y cronología en el contexto de la vertiente mediterránea. En M. Bea, R. Domingo, C. Mazo, L. Montes y J. M. Rodanés (Eds.). De la mano de la Prehistoria. Homenaje a Pilar Utrilla Miranda (pp. 121-142). Monografías Arqueológicas. Prehistoria, 57. Zaragoza: Universidad de Zaragoza.

Villaverde, V. y Martínez-Valle, R. (1995). Características culturales y económicas del final del Paleolítico superior en el Mediterráneo español. En V. Villaverde (Ed.). Los últimos cazadores, transformaciones culturales y económicas durante el Tardiglaciar y el inicio del Holoceno en el ámbito mediterráneo (pp. 79-117). Alicante Patrimonio, 22. Alicante: Instituto de Cultura Juan Gil-Albert, Diputación Provincial de Alicante.

Villaverde, V. y Peña, J. L. (1981). Piezas con escotaduras del Paleolítico Superior valenciano (materiales del Museo del Prehistoria de Valencia). Serie de Trabajos Varios del SIP, 89. Valencia: Servicio de Investigación Prehistórica, Diputación Provincial de Valencia. Recuperado de: http:// mupreva.org/pub/100/es

Villaverde, V., Real, C., Roman, D., Albert, R. M., Badal, E., Bel, M. Á.,... y Pérez-Ripoll, M. (2019). The early Upper Palaeolithic of Cova de les Cendres (Alicante, Spain). Quaternary International, 515, 92-124. DOI: https://doi. org/10.1016/j.quaint.2017.11.051

Villaverde, V., y Roman, D. (2004). Avance al estudio de los niveles gravetienses de la Cova de les Cendres. Resultados de la excavación del sondeo (cuadros A/B/C-17) y su valoración en el contexto del Gravetiense mediterráneo ibérico. Archivo de Prehistoria Levantina, XXV, 19-59.

Villaverde, V., Sanchis, A., Badal, E., Bel, M. Á., Bergadà, M. M., Eixea, A.,... y Wild, E. M. (2021). Cova de les Malladetes (Valencia, Spain): New Insights about the Early Upper Palaeolithic in the Mediterranean Basin of the Iberian Peninsula. Journal of Paleolithic Archaeology, 4(1). DOI: https:// doi.org/10.1007/s41982-021-00081-W

Zilhão, J., Anesin, D., Aubry, T., Badal, E., Cabanes, D., Kehl, M.,... y Zapata, J. (2017). Precise dating of the Middleto-Upper Paleolithic transition in Murcia (Spain) supports late Neandertal persistence in Iberia. Heliyon, 3(11), e00435. DOI: https://doi.org/10.1016/j.heliyon.2017.e00435 
